\title{
KFK -48
}

KERNFORSCHUNGSZENTRUM

KARLSRUHE

JANUAR 1961

KFK 48

INSTITUT FUR NEUTRONENPHYSIK UND REAKTORTECHNIK

REACTOR PHYSICS RESEARCH WITH PULSED NEUTRON SOURCES

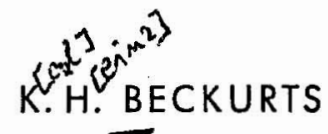




\title{
REACTOR PHYSICS RESEARCH WITH PULSED NEUTRON SOURCES
}

\author{
K. H. BECKURTS
}

Kernforschungszentrum, Karlsruhe

For the past 6 years pulsed neutron sources have been successfully used for studies of the kinetic behavior of neutrons in matter. Three main fields of interest have been particularly stressed: neutron lifetime measurementsin moderators; reactivity measurements on reactor systems; and

\section{Introduction}

The first pulsed accelerator to be used for neutron research was the $36^{\prime \prime}$ Berkeley cyclotron, as reported by Alvarez ${ }^{1}$ ). This author obtained bursts of neutrons from a $(\mathrm{d}, \mathrm{n})$-reaction by modulation of the cyclotron acceleration voltage. By placing detectors at different distances from a paraffin moderator surrounding the target, effects of neutrons of different velocities could be studied. During the past twenty years, the art has considerably improved and expanded; there are more than 60 pulsed sources in use today in different branches of neutron and reactor physics. Their main uses may be classified as follows:

\subsection{SPECTROMETRY OF SLOW AND INTERMEDIATE ENERGY NEUTRŌNS}

These spectrometers make use of the enormous neutron burst intensities available from high-current electron linear accelerators (using mostly uranium targets) or from high-energy proton accelerators. The fast neutrons, which are primarily produced, are slowed down into the intermediate and slow energy region by a small hydrogenous moderator close to the target; energy analysis is done by the time-of-flight technique using flight path lengths up to more than 150 meters. Resolutions better than $0.01 \mu \mathrm{s} / \mathrm{m}$ (corresponding to $\Delta E / E=2.8 \%$ at $E=10 \mathrm{keV}$ ) have been reported. These spectrometers are used for total and partial neutron cross section measurements; they have hitherto delivered a neutron spectra measurements by time-of-flight techniques. A number of most important results has been obtained, particularly in the field of neutron thermalisation research. The present status of pulsed source techniques and some of the more relevant results will be discussed.

wealth of cross section data and will certainly continue to do so for many years. The main representatives at present are the Saclay $^{2}$ ) and Harwell $^{3}$ ) linear accelerator spectrometers, the Nevis synchrocyclotron spectrometer ${ }^{4}$ ) and the KAPL betatron spectrometer $\left.{ }^{5}\right)$. Some Russian machines have been described $\left.{ }^{6}\right)$. Yale University and Rensselear Polytechnic Institute will soon obtain powerful electron linear accelerators which may outdo today's sources by a factor of 10 in intensity (see Nucleonics 18, 8 (1960) 57).

In spite of the fact that these spectrometers contribute very important basic nuclear data to reactor physics, they are considered outside the scope of this paper and will not be discussed further.

\subsection{FAST NEUTRON SPECTROMETRY}

As it is known, fast neutrons of practically any desired energy can be obtained from $(p, n)$ - or $(\mathrm{d}, \mathrm{n})$ - reactions on suitable targets bombarded with protons or deuterons from van de Graaffgenerators. Therefore, for many cross-section measurements the time-of-flight technique involving a pulsed source is not necessary. It has however succesfully been used

1) L. W. Alvarez, Phys. Rev. 54 (1938) 609.

2) P. Billaud et al., Geneva 1958 P/1186.

3) M. J. Poole and E. R. Wiblin, Geneva 1958 P/59.

4) J. Rainwater et al., Rev. Sci. Instr. 31 (1960) 481.

5) M. L. Yeater, E. R. Gärttner and G. C. Baldwin, Rev. Sci. Instr. 28 (1957) 514.

6) V. V. Vladimirski and V. V. Sokolovski, Geneva 1958 $\mathrm{P} / 2041$. 
- to study the spectrum of outgoing neutrons from a nuclear reaction (e.g. inelastic neutron scattering, fission neutron spectrum) ${ }^{7}$ )

- to improve the signal-to-noise-ratio in capture and fission cross section measurements ${ }^{8}$ )

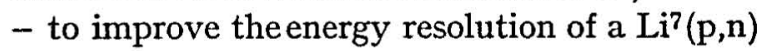
neutron source in the $\mathrm{keV}$ region ${ }^{9}$ ).

In order to obtain good resolution, pulse widths have to be of the order of millimicroseconds and many experimental problems of detecting the neutrons and timing the events arise. An excellent review of the associated problems of fast neutron spectroscopy is given in the corresponding chapters of Marion and Fowler's recent book ${ }^{10}$ ); see also Rybakov and Sydorovi1). No further treatment of this subject is intended here.

1.3. Investigation of thermal neutron diffusion parameters in moderators by measurement of neutron lifetimes.

1.4. Reactivity measurements on reactor systems by measurements of prompt reactor periods.

1.5. Measurements of neutron spectra from moderator and reactor systems by the time-offlight method.

In the following we shall deal with items 1.3, 1.4. and 1.5. which are essentially all applications of pulsed source techniques to reactor physics. We intend to give a general review of the methods which have been developed and of some of the more relevant results. We do not plan to give details of the reactor theory underlying many of the measurements. Reference is made to the orginal articles quoted in the text and especially to two excellent review articles covering all work done up to early 1958 : 2063.

7) L. Cranberg and J. S. Levin, Phys. Rev. 109 (1958)

8) B. C. Diven, Geneva 1958 P/667.

9) W. M. Good, J. H. Neiler and J. H. Gibbons, Phys. Rev. 109 (1958) 926.

10) J. B. Marion and J. L'. Fowler, Fast Neutron Physics (New York, 1960).

11) B. V. Rybakov and V. A. Sydorov, Fast Neutron Spectroscopy (New York, 1960).

12) G. F. v. Dardel and N. G. Sjöstrand, Progr. Nucl. En. 1, 2 (1958) 183.

13) M. J. Poole, M. S. Nelkin and R. S. Stone, Progr. Nucl. En. 1, 2 (1958) 91.
"Diffusion measurements with pulsed neutron sources" by G. F. v. Dardel and N. G. Sjöstrand ${ }^{12}$ ).

"The measurement and theory of reactor spectra" by M. J. Poole, M. S. Nelkin and R. S. Stone $\left.{ }^{13}\right)$.

\section{Investigations of Thermal Neutron Diffusion Parameters in Moderators}

\subsection{GENERAL}

If a burst of fast neutrons is fed into a moderator a slowing down and thermalisation of the neutron field occurs until an asymptotic state is established in which a characteristic neutron distribution in space and energy exists. This distribution is called a "thermal neutron flux", it will decay exponentially with a time constant $\alpha\left(\sec ^{-1}\right) ; 1 / \alpha$ is the "effective thermal neutron lifetime". If the geometrical dimensions of the moderator are characterized by its "buckling" $B^{2}$ (see fig. 1), the experimentally observed decay constants can be fitted in the following way:

$$
\alpha=\alpha_{0}+D_{0} B^{2}-C B^{4}+\text { higher terms . }
$$

$\alpha_{0}$ is the decay constant which would be observed in an infinite medium $\left(B^{2}=0\right)$ and is entirely due to absorption; for $1 / v$-absorption we have just

$$
\alpha_{0}=v_{0} \Sigma_{\mathrm{a}}\left(v_{0}\right)
$$

The remaining terms describe the neutron leakage from a finite moderator. If this could
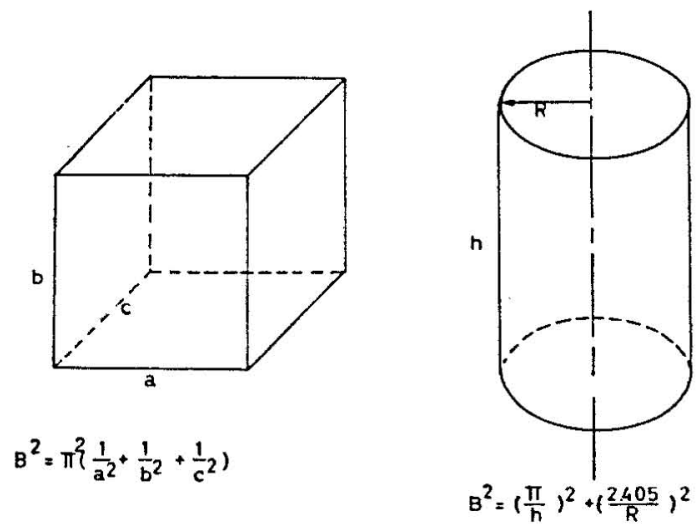

Fig. 1. Geometric buckling $B^{2}$ for various simple geometries. "Effective" dimensions have to be used, i.e. the actual dimensions must be increased by extrapolation lengths. 
be exactly described by elementary diffusion theory and if the asymptotic neutron spectrum were a Maxwellian with the moderator temperature, the second term on the right side would correctly describe the effects of leakage on the decay constant, since $D_{0}$ is the average of the energy dependent diffusion coefficient $D(E)$ :

$$
D_{0}=\frac{\int_{0}^{\infty} D(E) M(E) \mathrm{d} E+}{\int_{0}^{\infty} \frac{1}{v} M(E) \mathrm{d} E} .
$$

Careful experimental and theoretical work however shows clearly that higher terms in $B^{2}$, especially a $B^{4}$ term, have to be considered with smaller dimensions of the moderator. This is due to

- transport theory corrections to elementary diffusion theory which become important at large $B^{2}$.

- the "diffusion cooling" of neutrons.

In a moderator with small dimensions the main effect which removes neutrons is leakage. Since a faster neutron will escape from the moderator more probably than a slower one, the moderator continuously loses neutrons which are "hotter" than the neutrons inside. This loss is partially compensated by the coupling through collisions between the neutron gas and the moderator. As a result of these two counteracting processes a shift of the neutron spectrum below the equilibrium Maxwellian occurs which will be the larger the worse the thermalisation properties of the moderator and the more pronounced the leakage effects are. This "diffusion cooling" reduces the leakage rate.

Nelkin ${ }^{14}$ ) has given an essentially exact treatment of the two above-mentioned effects for simple moderators. In restricting to terms of order $B^{4}$, he shows that the constant $C$ can be written

$$
C=C_{\mathbf{D}}+C_{\mathbf{T}}
$$

$\dagger M(E)=\frac{E}{(k T)^{2}} \mathrm{e}^{-E / k T} \quad(T:$ moderator temperature $)$. where $C_{\mathbf{D}}$ describes the "diffusion cooling" and $C_{\mathrm{T}}$ the "transport theory" contribution to the $B^{4}$ term. Extrapolating from Nelkin's results it can be assumed that $C_{\mathrm{T}} \ll C_{\mathrm{D}}$ for most moderators of interest. In what follows we shall therefore identify $C$ and $C_{\mathbf{D}}$.

As Nelkin has further shown ${ }^{15}$ ), the diffusion cooling constant $C$ can be correlated in an approximate manner to a quantity $M_{2}$ which is a kind of "mean squared energy loss per collission" and therefore a fundamental quantity characteristic for the thermalisation power of a moderator: If $D(E) \sim E^{\alpha}$, Nelkin finds

$$
C=\frac{\left(\alpha+\frac{1}{2}\right)^{2} \sqrt{\pi} D_{0}^{2}}{v_{0} M_{2}}
$$

with

$$
v_{0}=\sqrt{\frac{2 k T}{m_{n}}}
$$

and

$M_{2}=\frac{1}{(k T)^{2}} \int_{0}^{\infty} \int_{0}^{\infty} \Sigma_{\mathrm{s}}\left(E \rightarrow E^{\prime}\right)\left(E^{\prime}-E\right)^{2} M(E) \mathrm{d} E \mathrm{~d} E^{\prime}$.

The analysis of $\alpha$ vs. $B^{2}$ curves measured on pure moderators therefore yields

\section{the absorption cross section}

the average thermal neutron diffusion coefficient, which can be combined with the absorption cross section to obtain the diffusion length

the "thermalisation power" $M_{2}$.

An exact determination of these parameters is indispensable if the use of a moderator for a thermal reactor is considered.

For such an analysis, the geometric buckling of a particular assembly has to be computed using the method outlined in fig. 1. This is a straightforward matter if the extrapolation length is energy independent. For moderators with a strongly energy dependent transport mean free path special considerations are necessary, as for example these made for water by Gelbard ${ }^{16}$ ).

14) M. S. Nelkin, Nucl. Sci. Eng. 7 (1960) 210.

15) M. S. Nelkin, J. Nucl. En. 8 (1958) 48.

16) E. Gelbard, J. Davis and J. Pearson: Westinghouse Atomic Power Division (USA) Report WAPD-T-1065 (1959). 


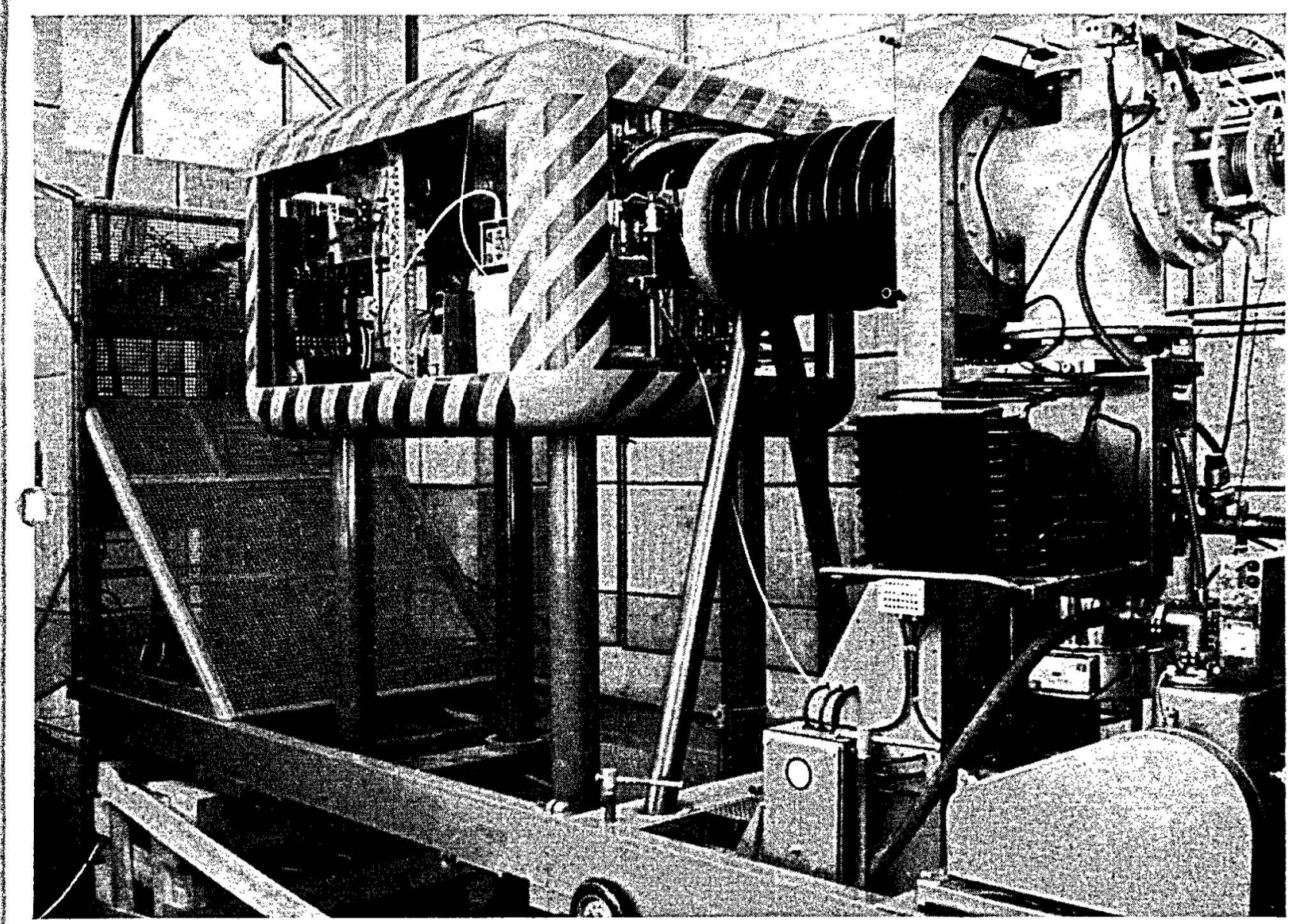

Fig. 2. Versatile $200 \mathrm{keV}$ neutron generator at Karlsruhe.

\subsection{INSTRUMENTATION ${ }^{\dagger}$}

The apparatus for $\alpha$-measurements consists of a pulsed neutron source, neutron detectors and a suitable time analyzer. As pulsed sources it is nowadays customary to use low voltage, high current deuteron accelerators with pulsed ion sources. These accelerators give sufficient neutron intensities, especially when used with tritium targets, and can be made highly flexible. Requirements as to pulse length, yield and repetition rate are about as follows:

Repetition rate: Since $\alpha$ 's between 100 and $10^{5} / \mathrm{sec}$ have to be observed, and since one observation interval should be of the order of $10 / \alpha$, the repetition rate should be variable between 10 and $10^{4} / \mathrm{sec}$.

Pulse length: The pulse length will normally be

$\dagger$ see also 3.2. and 4.2 . a fraction of $\alpha$, at the maximum being equal to $\alpha$, e.g. 10 millisec $-10 \mu$ sec.

Intensity: In order to have reasonable statistics, the average neutron intensity should be at least $10^{8}-10^{9} / \mathrm{sec}$. It should however not exceed $10^{10} / \mathrm{sec}$ since this will cause to high counting rates and corresponding counting losses. This problem has been carefully studied by Keepin ${ }^{17}$ ).

A typical pulsed neutron source has been developed by W. Eyrich at Karlsruhe (fig. 2). Deuterons from a r.f. ion source are accelerated to $200 \mathrm{keV}$ in a horizontal one-stage acceleration tube. The source is easily movable on wheels and can be varied in height. Target extension tubes up to 4 meters length have been successfully

17) G. R. Keepin, Symp. on Application of Pulsed Neutron Techniques, Berkeley (1958) (UCRL-5665). 


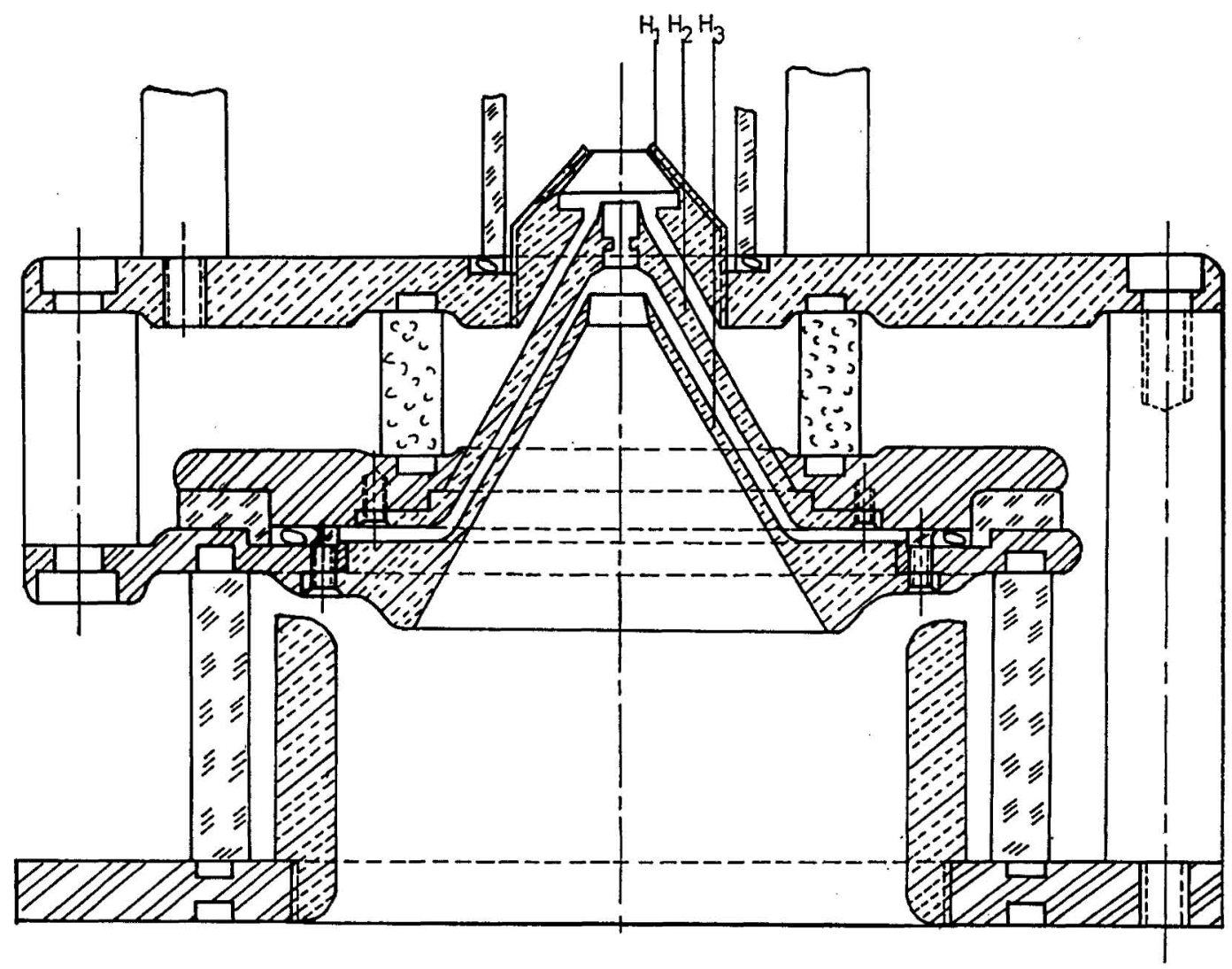

Fig. 3. Ion extraction system at the r.f. ion source of the generator from fig. 2 .

used; this makes possible the use of the source with reactors where the shield has to be penetrated. Pulsing of the r.f. ion source is achieved by pulsing the extraction voltage. Details of the extraction system can be seen in fig. 3. The extraction electrode $\mathrm{H}_{2}$ is normally on zero potential; during pulses it is driven up to $-15 \mathrm{kV}$. Ion currents up to $10 \mathrm{~mA}$ (measured at the target) have been obtained, the risetime of the ion pulse being about $0.5 \mu \mathrm{sec}$. Electrode $\mathrm{H}_{3}$ is always $+1000 \mathrm{~V}$ positive against $\mathrm{H}_{2}$. This is ineffective during pulse-on-time, however prevents ions from drifting into the acceleration tube during the pauses between bursts. In this way, a "background" current as low as $10^{-5}$ of the "normal pulse" current is obtained, which is very important for this type of work. Using tritium targets and a 1:10 duty ratio this source can furnish more than $10^{11} \mathrm{n} / \mathrm{sec}$ which is more than sufficient for most applications. The burst length is determined by an univibrator in the high voltage terminal which can be easily changed; the repetition rate is arbitrarily and determined by the frequency with which the optical transmission system is triggered.

A number of small pulsed accelerators are commercially available:

The PN 400 van de Graaff (High Voltage Engineering Corporation).

The $400 \mathrm{keV}$-Cockroft-Walton-Accelerator (Arco/HVEC).

Pulsed accelerators are also built by Häfely, Basel; Texas Nuclear Corporation, Austin; Sames, Grenoble; and others. We do not intend to review the properties of these and other accelerators here. Different types of ion sources and of pulsing systems have been used. A particularly interesting development is being carried out by Arco Corporation in collaboration with LASL for a very versatile accelerator to be used by LASL $^{17}$ ). 


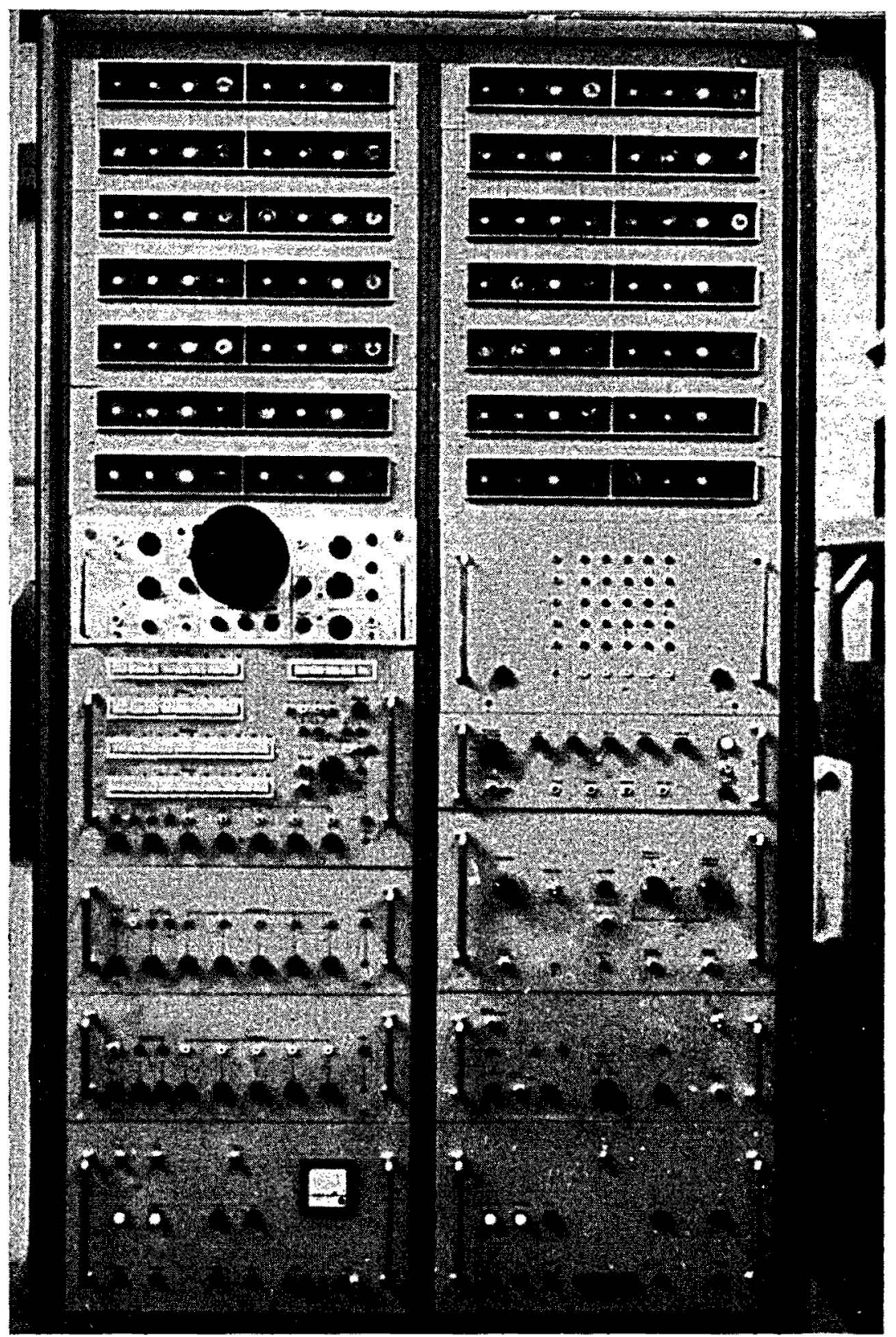

Fig. 4. 25 channel analyzer used a KarsIruhe.

This facility will give pulsed beams of $350 \mathrm{keV} \mathrm{deu-}$ terons with intensities up to $5 \mathrm{~mA}$ and yields, by different techniques, bursts from $10^{-8}-3 \times 10^{-3}$ sec long with repetition rates from $3 \times 10^{6}$ down to $10 / \mathrm{sec}$.

Detectors for pulsed moderator work do not pose special problems. Most authors have used
$\mathrm{BF}_{3}$ gas counters which are commercially available in a variety of models. The Oak Ridge group $^{22}$ ) has successfully used small $\mathrm{Li}^{6}$ (Eu) scintillators. With the tendency to measure diffusion parameters up to very high -moderator temperatures (i.e. up to $800^{\circ} \mathrm{C}$ in graphite and beryllium; up to $300-400^{\circ}$ in organic moderators) 
the demand for a temperature-resistant prompt neutron detector arises. Fission detectors for temperatures up to $300^{\circ} \mathrm{C}$ are available commercially, and it may be necessary to use these in combination with suitable cooling techniques. converter in connection with a multichannel pulse height analyzer. If this is done care must be taken in order to achieve sufficient linearity and stability. A system having high stability and being linear to better than $1 \%$ has been recently described $\left.{ }^{21}\right)$.

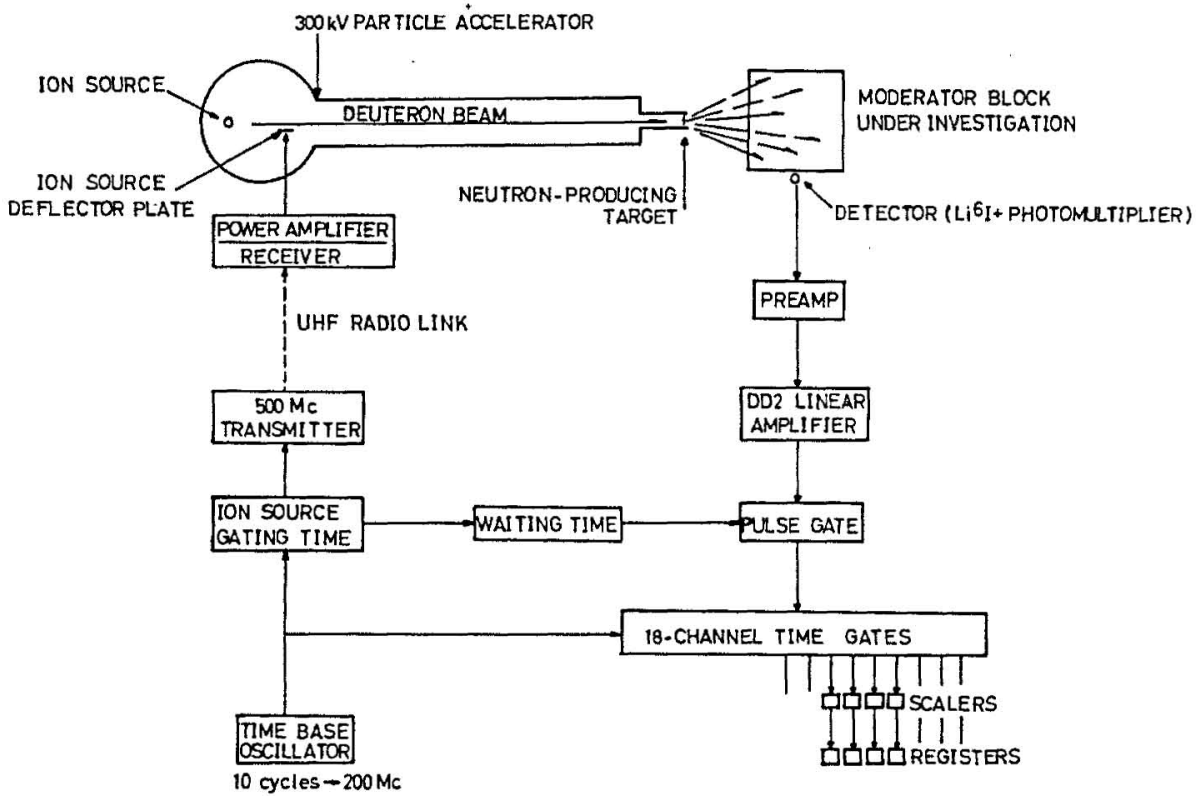

Fig. 5. Block diagram of the equipment used by de Saussure and Silver ${ }^{22}$ ).

The time analyzer must be of the multichannel type and should have between 20-40 channels, each variable in width between $5 \mu$ sec and 5 msec. A number of strictly digital analyzers particularly designed for this type of work have been developed $\left.{ }^{18,19,20}\right)$. An important requirement for such an analyzer is a reasonably low deadtime which should be smaller than $5 \mu$ sec. A 25-channel analyzer with $1 \mu \mathrm{s}$ deadtime now in use at Karlsruhe is shown in fig. 4. Each channel has a Burroughs beam switching tube scale of ten followed by several Dekatrons. The channel width is adjustable between $4 \mu \mathrm{sec}$ and several seconds.

If counting rates are reasonably low the time analysis can be done by a time-to-height

18) G. F. von Dardel, Appl. Sci. Res. B3 (1953) 209.

19) F. Glass, ORNL-2480 (1958) 22.

20) E. Gatti, Rev. Sci. Instr. 24 (1953) 345.

21) K. H. Beckurts, Nukleonik 2 (1960) 129.

22) G. de Saussure and E. G. Silver, ORNL-2641 (1959).

\subsection{A MEASUREMENT ON ROOM-TEMPERATURE BERYLLIUM}

As an example of a moderator experiment with the pulsed source technique we consider the work on room temperature beryllium by de Saussure and Silver ${ }^{22}$ ). These authors followed the neutron decay from thirteen cubical blocks of beryllium having fundamental-mode bucklings ranging from $0.8 \times 10^{-2}$ to $7.2 \times 10^{-2} \mathrm{~cm}^{-2}$. The general setup of their experimental equipment is shown in fig. 5 . The pulsed source and the detector are located outside the moderator blocks, normally in the middle of adjacent side planest. This arrangement minimizes the amount of "higher harmonics" contamination of the neutron flux decay. Figs. 6 and 7 show detailed

$\dagger$ Normally, the surfaces of moderator blocks are covered by a neutron absorber like cadmium in order to prevent room scattered neutrons from reentering the block. It is not clear whether this was done here. 


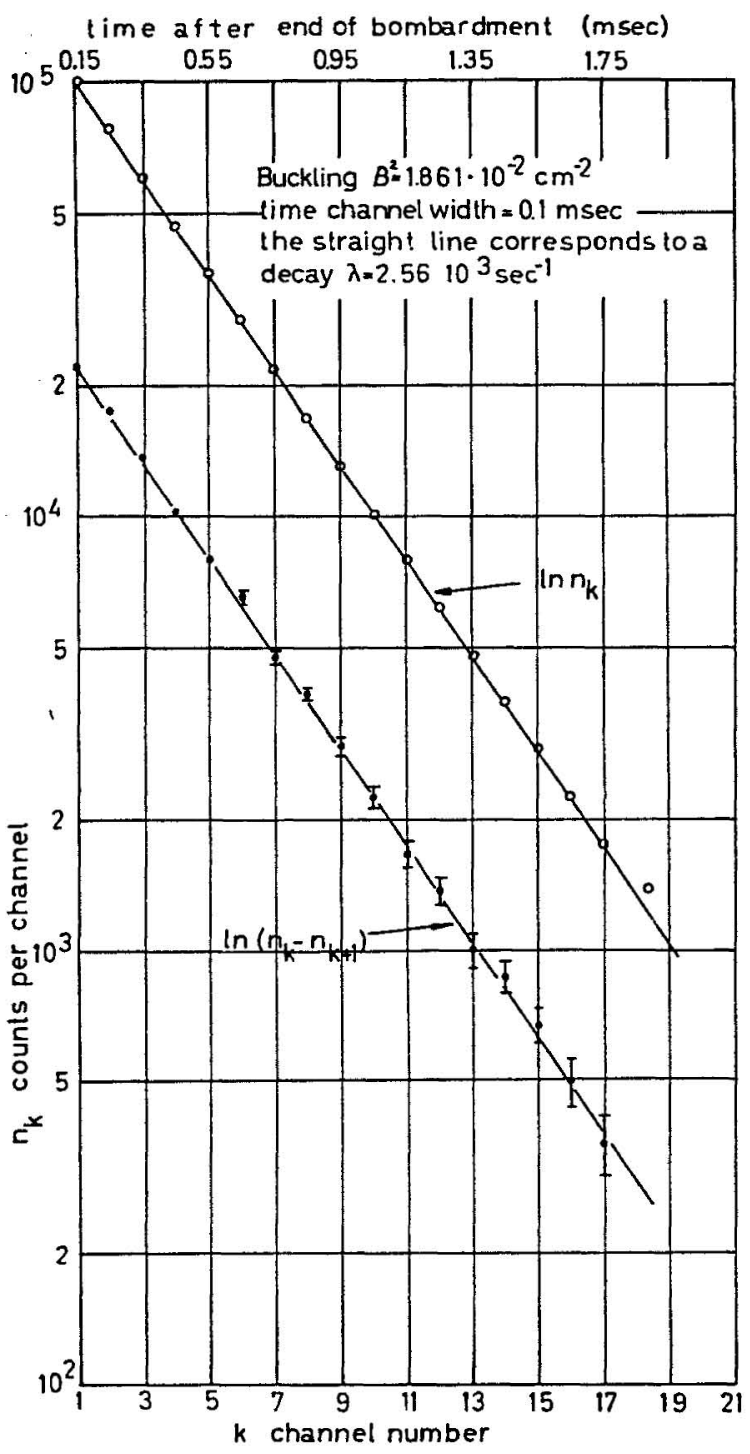

Fig. 6. Decay of the neutron flux in a beryllium assembly $14 \frac{3}{8} \times 14 \frac{3}{8} \times 16$ in. $\left(\right.$ from $\left.^{22}\right)$ ).

neutron flux decay curves obtained from the largest and the smallest assembly under investigation. While a very clean decay is observed from the large block, a considerable background of room scattered neutrons is observed in the case of the small assembly; this has to be eliminated before the decay constant can be determined. These authors used the Cornell ${ }^{23 a}$ ) method for the $\alpha$ determination, while most other authors use the method of Peierls ${ }^{23 b}$ ).

A plot of $\alpha$ vs $B^{2}$ as obtained from these

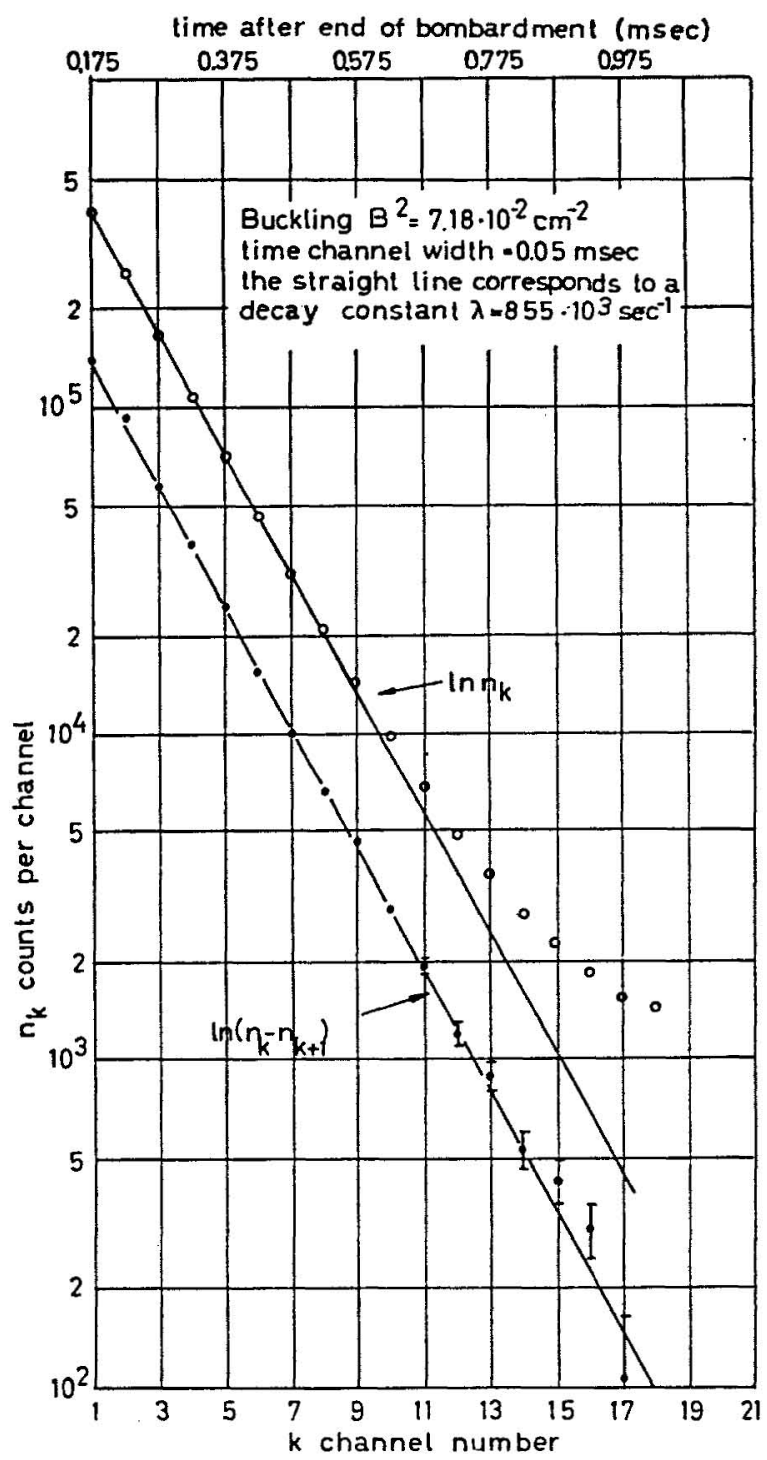

Fig. 7. Decay of the neutron flux in a beryllium assembly $5 \frac{3}{4} \times 8 \times 8 \frac{5}{8}$ in. $\left(\right.$ from $\left.^{22}\right)$ ).

measurements is shown in fig. 8 . The curve shows clearly the deviations from the straight line which demonstrate the "diffusion cooling" effect. By a least squares fit, the following diffusion parameters are obtained (at a density $\left.1.85 \mathrm{~g} / \mathrm{cm}^{3}\right)$ :

$$
\begin{aligned}
& \alpha_{0}=288 \pm 60 \mathrm{sec}^{-1} \\
& D_{0}=(1.25 \pm 0.06) \times 10^{5} \mathrm{~cm}^{2} \mathrm{sec}^{-1} \\
& C=(1.40 \pm 1) \times 10^{5} \mathrm{~cm}^{4} \mathrm{sec}^{-1}
\end{aligned}
$$

23a) R. G. Cornell, ORNL-2120 (1956).

23b) R. Peierls, Proc. Roy. Soc. Lond. A 149 (1935) 467. 
TABLE i

Results of pulsed experiments on beryllium $\left(1.85 \mathrm{~g} / \mathrm{cm}^{3}\right)$

\begin{tabular}{l|l|c|c|c|c}
\hline Year & \multicolumn{1}{|c|}{ Author } & $\begin{array}{c}\alpha_{0} \\
\left(\mathrm{sec}^{-1}\right)\end{array}$ & $\begin{array}{c}D_{0} \\
\left(\mathrm{~cm}^{2} \mathrm{sec}^{-1}\right) \times 10^{5}\end{array}$ & $\begin{array}{c}C \\
\left(\mathrm{~cm}^{4} \mathrm{sec}^{-1}\right) \times 10^{5}\end{array}$ & $\begin{array}{c}B^{2} \mathrm{range} \\
\left(\mathrm{cm}^{-2}\right)\end{array}$ \\
\hline & & - & $1.17 \pm 0.05$ & $2.93 \pm 1.0$ & $0.008-0.061$ \\
1955 & Antonov $\left.{ }^{26}\right)$ & 150 & 1.25 & 0 & $0.005-0.036$ \\
1956 & Campbell and Stelson $\left.{ }^{27}\right)$ & $270 \pm 19$ & $1.24 \pm 0.04$ & $3.90 \pm 0.8$ & $0.003-0.041$ \\
1958 & Kloverstrom $\left.{ }^{28}\right)$ & $288 \pm 60$ & $1.25 \pm 0.06$ & $1.40 \pm 1.0$ & $0.008-0.072$ \\
1959 & de Saussure and Silver & & & \\
\hline
\end{tabular}

The value of $\alpha_{0}$ leads to a microscopic absorption cross section of $11 \pm 2$ millibarn which is only slightly higher than the cross section of pure $\left.\mathrm{Be}^{24}\right)$. The measured $D_{0}$ is close to the theoretical value $1.21 \times 10^{5} \mathrm{~cm}^{2} \mathrm{sec}^{-1}$ as calculated by Bhandari ${ }^{25}$ ). The diffusion cooling

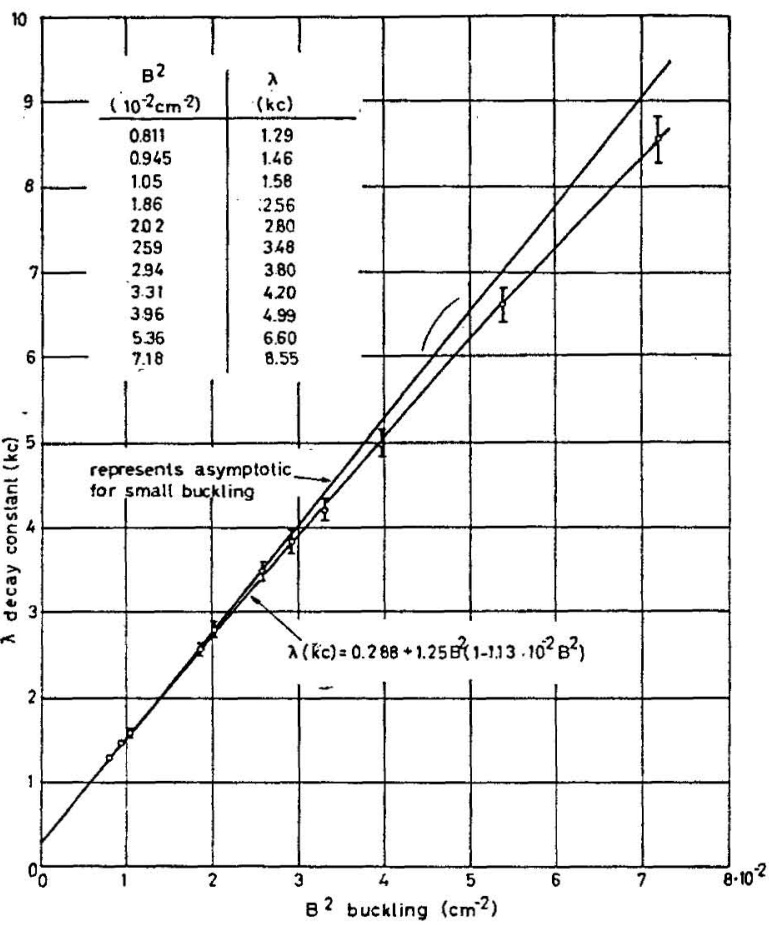

Fig. 8. Thermal neutron decay constant as a function of buckling for room temperature beryllium (from ${ }^{22}$ )). coefficient is in excellent agreement with the value $1.4 \times 10^{5} \mathrm{~cm}^{4} \mathrm{sec}^{-1}$ as calculated in an approximate manner by Nelkin ${ }^{15}$ ) who employed a Debye model for the lattice vibrations in beryllium.

It is interesting to compare these results with i) the results of other investigations on beryllium (table 1).

We can disregard the discrepancies in $\alpha_{0}$ which may be due to different purity grades of the materials. There are, however, considerable discrepancies in the $D_{0}$ and particularly the $C$ values. While de Saussure and Silver ${ }^{22}$ ) state that the older results probably involve errors in the interpretation of data, the discrepancies between the more recent ORNL and UCRL data still persists and cannot be explained. As we shall see later, the situation is very similar for other moderators.

De Saussure and Silver have also performed measurements on beryllium at temperatures

$\dagger$ A more recent measurement by Andrews ${ }^{29}$ ) reconfirms these results.

24) D. J. Hughes and R. B. Schwartz, BNL-325 (1958).

25) R. C. Bhandari, J. Nucl. En. 6 (1957) 104.

26) A. V. Antonov et al., Geneva 1955 P/661.

27) E.C.Campbelland P.H.Stelson, ORNL-2076(1956)32.

${ }^{28}$ ) T. T. Komoto and F. Kloverstrom, Trans. Am. Nucl. Soc. 1 (1958) 1.

29) W.M. Andrews, Trans. Am. Nucl. Soc. 3, 1 (1960) 161.

TABLE 2

Results of different pulsed experiments on graphite $\left(1.6 \mathrm{~g} / \mathrm{cm}^{3}\right)$

\begin{tabular}{|c|c|c|c|c|c|}
\hline Year & Author & $\begin{array}{c}\alpha_{0} \\
\left(\sec ^{-1}\right)\end{array}$ & $\begin{array}{c}D_{0} \\
\left(\mathrm{~cm}^{2} \mathrm{sec}^{-1}\right) \times 10^{5}\end{array}$ & $\frac{C}{\left(\mathrm{~cm}^{4} \sec ^{-1}\right) \times 10^{5}}$ & $\begin{array}{c}B^{2} \text { range } \\
\left(\mathrm{cm}^{-2}\right) \times 10^{3}\end{array}$ \\
\hline $\begin{array}{l}1955 \\
1956 \\
1960\end{array}$ & $\begin{array}{l}\text { Antonov }^{26} \text { ) } \\
\text { Beckurts }^{31} \text { ) } \\
\text { Starr and Price } \\
\text { (2) }\end{array}$ & $\begin{aligned} 82 & \pm 3 \\
127 & \pm 1 \\
71.2 & \pm 0.9\end{aligned}$ & $\begin{array}{l}2.07 \pm 0.03 \\
2.13 \pm 0.02 \\
2.06 \pm 0.02\end{array}$ & $\begin{array}{l}12.5 \pm 2.0 \\
16.3 \pm 2.5 \\
12.4 \pm 2.2\end{array}$ & $\begin{array}{l}1.0-40 \\
0.7-5.5 \\
1.6-27.5\end{array}$ \\
\hline
\end{tabular}


different from room temperature ${ }^{30}$ ). Fig. 9 shows the variation of the transport mean free path of beryllium with temperature as obtained from pulsed measurements between -46 and $+511^{\circ} \mathrm{C}$.

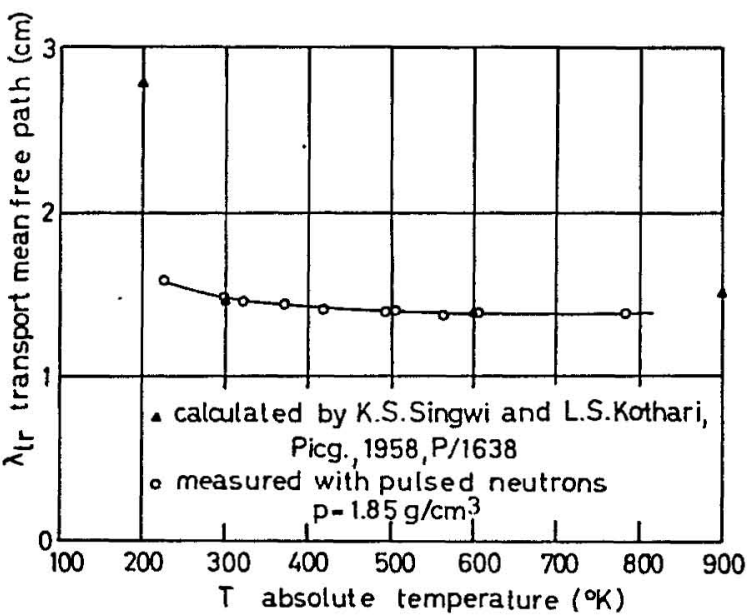

Fig. 9. Transport mean free path of thermal neutrons in beryllium as a function of temperature $\left(\right.$ from $\left.{ }^{30} \mathrm{y}\right)$.

\subsection{RESULTS ON DIFFERENT MODERATORS}

\subsubsection{Graphite}

Table 2 summarizes different results on room temperature graphite.

While these three determinations are in reasonable agreement, two recent measurements ${ }^{33,34}$ ) show a diffusion cooling coefficient which is larger by a factor of two. The reasons for these discrepancies are not yet understood. Possible causes for errors and discrepancies which have to be checked are

- the role of a $B^{6}$-term

- the importance of data evaluation schemes

- the effects of higher harmonics and of background neutrons.
It might also be possible that graphites manufactured by different methods have different diffusion parameters. Still much experimental and theoretical work has to be done in order to clear these discrepancies up. For graphite this is particularly important since the pulse method is sometimes used for routine measurements of absorption cross sections, where a high precision is desired. A more precise value for the diffusion cooling coefficient $C$ is also important in order to check current thermalisation theories for graphite: The theoretical value for $C$, as computed by Nelkin ${ }^{15}$ ) in the Debye crystal approximation, is $14 \times 10^{5} \mathrm{~cm}^{4} \mathrm{sec}^{-1}$.

\subsubsection{Water}

Results of various experiments on (ordinary) water are summarized in table 3 .

It is seen that the values are in excellent agreement among each other; this holds especially for the two most recent determinations. Küchle's result yields $326 \pm 6$ millibarn for the proton capture cross section at $2200 \mathrm{~m} / \mathrm{sec}$ and $2.72 \pm 0.08 \mathrm{~cm}$ for the diffusion length, which compares very well with a directly measured value of $\left.2.72 \pm 0.03 \mathrm{~cm}^{39}\right)$. From the diffusion 115.

30) G. de Saussure and E. G. Silver, ORNL-2842 (1959)

31) K. H. Beckurts, Nucl. Sci. Eng. 2 (1957) 516.

32) E. Starr, G. A. Price, Trans. Am. Nucl. Soc. 2, 2 (1959) 125.

33) M. Küchle, personal communication (1960).

34) G. Denielou, personal communication (1960).

35) G. F. v. Dardel and N. G. Sjöstrand, Phys. Rev. 96 (1954) 1245.

36) A. Bracci and C. Coceva, Nuovo Cim. 4, X (1956) 59.

37) W. H. Dio, Nukleonik 1 (1958) 13.

38) M. Küchle, Nukleonik 2 (1960) 131 .

${ }^{39}$ ) K. H. Beckurts and O. Klüber, Zs. Natf. 132 (1958) 822.

TABLE 3

Results of different pulsed experiments on water $\left(22^{\circ} \mathrm{C}\right)$

\begin{tabular}{|c|c|c|c|c|c|}
\hline Year & Author & $\begin{array}{c}\alpha_{0} \\
\left(\mathrm{sec}^{-1}\right)\end{array}$ & $\begin{array}{c}D_{0} \\
\left(\mathrm{~cm}^{2} \mathrm{sec}^{-1}\right)\end{array}$ & $\begin{array}{c}C \\
\left(\mathrm{~cm}^{4} \sec ^{-1}\right)\end{array}$ & $\begin{array}{c}B^{2} \text { range } \\
\left(\mathrm{cm}^{-2}\right)\end{array}$ \\
\hline 1954 & v. Dardel and Sjöstrand ${ }^{35}$ ) & 4892 & $36340 \pm 750$ & $7300 \pm 1500$ & $0.1-0.7$ \\
\hline 1955 & Antonov ${ }^{26}$ ) & 4831 & $35000 \pm 1000$ & $4000 \pm 1000$ & $0.09-0.93$ \\
\hline 1956 & Bracci and Coceva ${ }^{36}$ ) & 4950 & $34850 \pm 1100$ & $3000 \pm 1000$ & $0.09-0.96$ \\
\hline 1959 & $\mathrm{Dio}^{37}$ & 4808 & $35450 \pm 600$ & $3700 \pm 700$ & $0.09-0.87$ \\
\hline 1960 & Küchle ${ }^{38}$ ) & 4785 & $35400 \pm 700$ & $4200 \div 800$ & $0.11-0.75$ \\
\hline
\end{tabular}


cooling coefficient a value of 30 barn per hydrogen atom for $M_{2}$ can be derived. This is the same as would be computed for a gas of mass 18 nuclei and shows that the molecular rotations in water are strongly hindered.

A few measurements in water at elevated

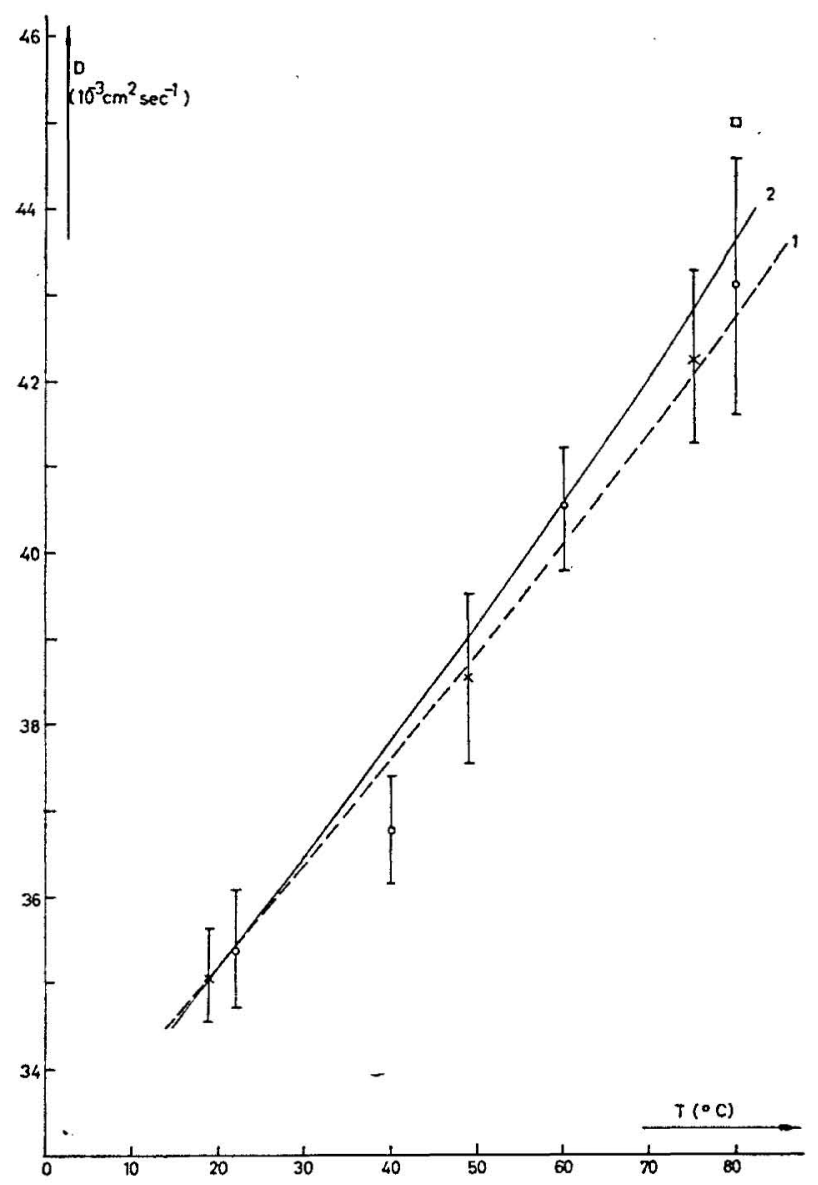

Fig. 10. Temperature dependence of the diffusion coefficient of thermal neutrons in water.

$\left.X: \mathrm{Dio}^{37}\right) \square:$ Antonov ${ }^{26}$ ) $O: \mathrm{Küchle}^{38}$ ).

The solid line is computed assuming a $1 / v$ behaviour of the transport cross section in water. temperatures have been made. The variation of the diffusion coefficient in the temperature region $20-80^{\circ} \mathrm{C}$ thus obtained is shown in fig. 10 .

The situation in water seems quite consistent so far. However, a very careful stationary measurement of the diffusion length has been recently published yielding $L=2.859 \pm 0.018 \mathrm{~cm}$ at $\left.25.9^{\circ} \mathrm{C}^{40}\right)$. Using $\sigma_{\mathrm{a}}=327$ millibarn, this would lead to a diffusion coefficient $D_{0}=$ $38800 \mathrm{~cm}^{2} \mathrm{sec}^{-1}$ at $22^{\circ} \mathrm{C}$, i.e. a result $10 \%$ higher than all the values from the pulsed experiments!

\subsubsection{Other moderators}

Beryllium oxide has been investigated by Iyengar et al. ${ }^{41}$ ) who found the following results (for a density $2.96 \mathrm{~g} / \mathrm{cm}^{3}$ )

$$
\begin{aligned}
\alpha_{0}= & 131.5 \mathrm{sec}^{-1} \\
D_{0}= & 1.18 \times 10^{5} \mathrm{~cm}^{2} / \mathrm{sec}\left(24^{\circ} \mathrm{C}\right) ; \\
& 1.36 \times 10^{5} \mathrm{~cm}^{2} / \mathrm{sec}\left(80^{\circ} \mathrm{C}\right) ; \\
& 1.60 \times 10^{5} \mathrm{~cm}^{4} / \mathrm{sec}\left(140^{\circ} \mathrm{C}\right) \\
C= & 3.85 \times 10^{5} \mathrm{~cm}^{4} / \mathrm{sec}\left(24^{\circ} \mathrm{C}\right) ; \\
& 7.5 \times 10^{5} \mathrm{~cm}^{2} / \mathrm{sec}\left(80^{\circ} \mathrm{C}\right) ; \\
& 12.4 \times 10^{5} \mathrm{~cm}^{4} / \mathrm{sec}\left(140^{\circ} \mathrm{C}\right)
\end{aligned}
$$

The reasons for the very strong increase of $C$ with temperature are not very well understood.

As a typical organic moderator Dowtherm A (Diphyl) has been investigated by Küchle ${ }^{37}$ ). The results obtained between $20^{\circ} \mathrm{C}$ and $180^{\circ} \mathrm{C}$ are given in table 4.

The results for $\alpha_{0}$ are consistent with a microscopic hydrogen absorption cross section of $333 \pm 5$ millibarn; this is higher than the pure hydrogen cross section due to impurities. The temperature dependence of the transport mean

40) K.S. Rockey and W.Skolnils, Nucl. Sci. Eng. 8(1960) 62 .

41) S.B.D. Iyengar etal., Proc. Ind. Acad. Sci. 45(1957) 215.

TABLE 4

Diffusion parameters of Dowtherm A

\begin{tabular}{l|c|r|rr}
\hline & $20^{\circ} \mathrm{C}$ & $80^{\circ} \mathrm{C}$ & $140^{\circ} \mathrm{C}$ & $180^{\circ} \mathrm{C}$ \\
\hline$\alpha_{0}\left(\mathrm{sec}^{-1}\right)$ & $2870 \pm 40$ & $2.780 \pm 40$ & $2600 \pm 60$ & $2530 \pm 70$ \\
$D_{0}\left(\mathrm{~cm}^{2} \mathrm{sec}^{-1}\right)$ & $49200 \pm 600$ & $60700 \pm 700$ & $74300 \pm 1100$ & $83800 \pm 1300$ \\
$C\left(\mathrm{~cm}^{4} \mathrm{sec}^{-1}\right)$ & $11900 \pm 2100$ & $12200 \pm 2400$ & $17700 \pm 4500$ & $22300 \pm 5700$ \\
\hline
\end{tabular}


free path as deduced from the measured $D_{0}$ is shown in fig. 11 in comparison to the calculations of Petrie et al.42). For $M_{2}$, a value of 50 barn per
$C$ was found to be $(0.00 \pm 0.04) \times D_{0}$; it is very surprising that no diffusion cooling was observed in this experiment.

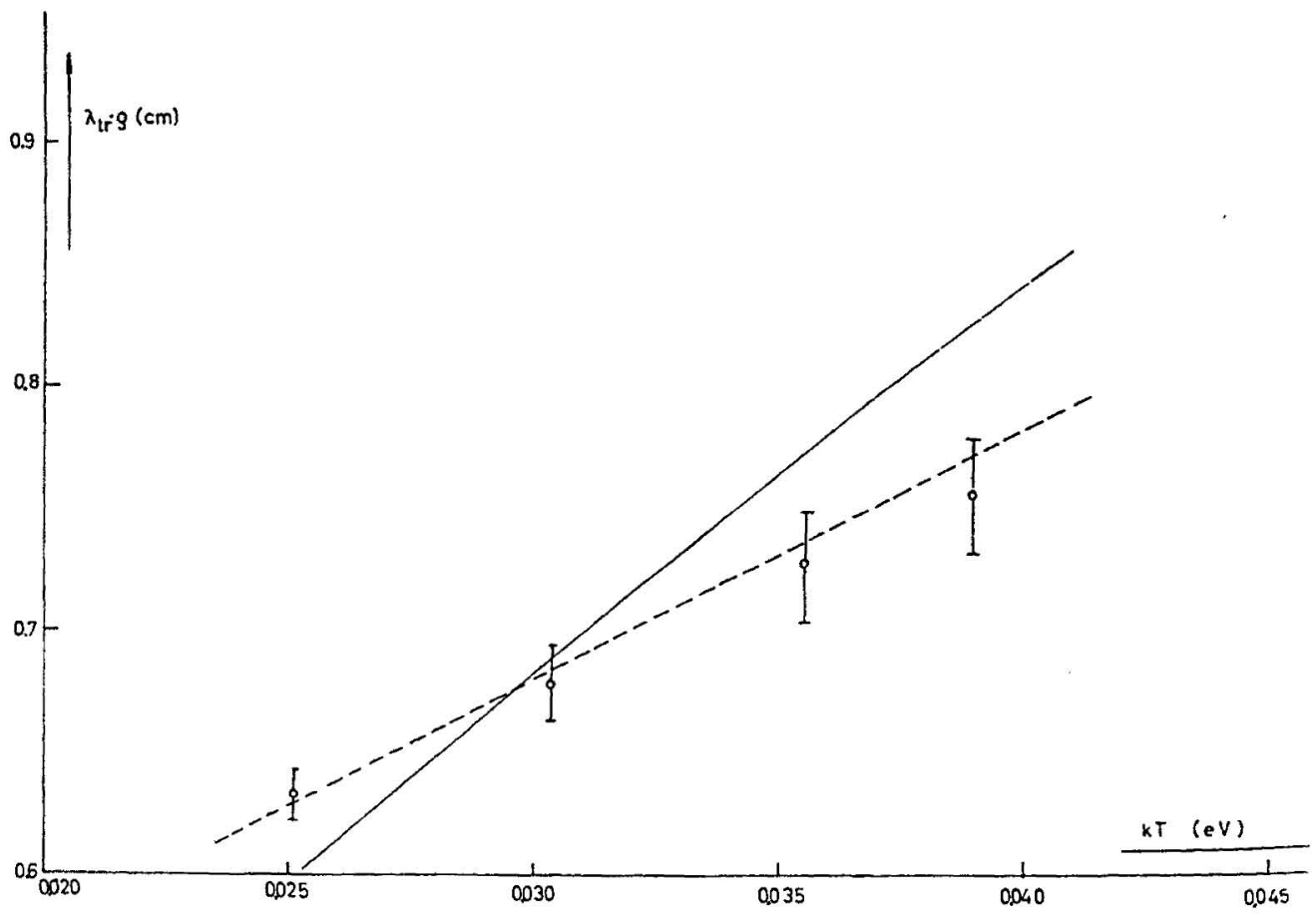

Fig. 11. Temperature dependency of the transport mean free path of thermal neutrons in Dowtherm A as measured by $\mathrm{Küchle}^{38}$ ). The solid line is computed using the method of Petrie et $a l .{ }^{42}$ ), while the broken line assume a $1 / v$ transport cross section.

hydrogen atom can be deduced from the measured $C$ values. This is somewhat higher than for water and indicates very good thermalisation properties of Dowtherm A.

The diffusion cooling coefficient for heavy water has been determined by Sjöstrand ${ }^{43}$ ) from measurements on very small assemblies. Employing the diffusion coefficient $D_{0}$ as known from other work $\left.{ }^{44}\right)$, he found $C=(3.5 \pm 0.8) \times$ $10^{5} \mathrm{~cm}^{4} \mathrm{sec}^{-1}$ at $20^{\circ} \mathrm{C}$. This is considerably smaller than would be expected for a monoatomic gas with mass 20 nuclei.

A measurement of the thermal neutron diffusion parameters in plexiglas has been reported by Seemann ${ }^{45}$ ). By observing the neutron decay from different cylindrical assemblies ranging in buckling from 0.04037 to $0.7061\left(\mathrm{~cm}^{-2}\right)$, the following diffusion parameters were determined: $\alpha_{0}=4.3 \times 10^{3} \mathrm{sec}^{-1}, \quad D_{0}=3.4 \times 10^{4} \mathrm{~cm}^{2} \mathrm{sec}^{-1}$.

\subsection{MEASUREMENTS OF THE GEOMETRICAL BUCKLING}

Hitherto we have considered only the case where the diffusion parameters are determined from $\alpha$ measurements on moderator assemblies of known, easily computable buckling. If the diffusion parameters - e.g. the $\alpha$ vs. $B^{2}$ curve of a moderator are known, a measurement of $\alpha$ yields the buckling of the system under investigation. This can be used to determine bucklings of assemblies with complicated boundary conditions which are likely to occur in reactor physics. The method has first been used by Beckurts ${ }^{46}$ ) who measured the change in

42) C. D. Petrie, M. L. Storm and P. F. Zweifel, Nucl. Sci. Eng. 2 (1957) 728.

43) N. G. Sjöstrand, Arkiv för Fysik 15 (1958) 145.

44) S. W. Kash and D. C. Woods, Phys. Rev. 90 (1953) 564.

45) K. W. Seemann, Trans. Am. Nucl. Soc. 2, 1 (1959) 69.

46) K. H. Beckurts, Zs. Natf. 11a (1956) 881. 
buckling which arises when a concentric ring of 4 absorbing rods is introduced into a moderator (graphite) of cylindrical shape. Sjöstrand et al. ${ }^{47}$ ) have employed this method to determine the geometrical bucklings of reactors having complicated shape and to study the extrapolation lengths at the surface of absorbing rods. Some studies of control rods in square shaped moderators have been done by the Oak Ridge group 48,49$)$. We shall not go into the details of these measurements since noresults of anygeneral physical importance can be obtained. We want to stress however the great possibilities of the pulse method for buckling determinations with regard to problems arising in special situations.

\subsection{CONCLUSIONS}

It has been shown that the pulsed source method is a powerful tool for investigations on moderators, and that many careful investigations have been carried out. However, still much work has to be done in order to cover more moderating materials and to increase the accuracy. Additional determinations of diffusion parameters are desirable for

- heavy water at room temperature and at elevated temperatures

- light water at temperatures above room temperature $\left(100-300^{\circ} \mathrm{C}\right)$

- organic moderators like Santowax R (Terphenyl), especially at elevated temperatures

- graphite at temperatures up to $800^{\circ} \mathrm{C}$.

Experiments in order to clarify discrepancies and to increase accuracy are necessary for

- graphite and beryllium in order to settle the diffusion cooling problem

- beryllium oxide as a reconfirmation of the strong dependence of $C$ on temperature

- light water in order to clarify the discrepancy with the recent diffusion length experiment. A very interesting contribution to this question has quite recently been given by Lopez, Beyster et al.50). Theseauthors have started a very careful remeasurement of the diffusion parameters in light water using an somewhat modified method: They inject fast neutron bursts into very large (up to $17 \frac{1}{2} \times 17 \frac{1}{2} \times 19 \frac{1}{4}$ inch) water tanks and perform measurements of the time-dependent neutron flux at different detector positions inside the tank, using a small fission detector which can easily be inserted into the system. The resulting space- and time-dependent flux distribution is analyzed into the "fundamental mode" and "higher harmonic" contributions by means of a special IBM 704 code. In this way decay curves of isolated modes are obtained which yield $\alpha$ values definitely free of modal effects. The following preliminary values for the diffusion parameters have been obtained $\left(\right.$ at $\left.22^{\circ} \mathrm{C}\right)$ :

$$
\begin{aligned}
& D_{0}=36800 \pm 400 \mathrm{~cm}^{2} \mathrm{sec}^{-1} \\
& C=4137 \pm 688 \mathrm{~cm}^{4} \mathrm{sec}^{-1} \\
& \sigma_{\mathrm{H}}=326 \pm 2 \mathrm{millibarn} .
\end{aligned}
$$

The values for $\sigma_{\mathrm{H}}$ and $C$ are in excellent agreement with those obtained by Küchle (table 3), while $D_{0}$ is about $4 \%$ larger. The diffusion length deduced from these results is $2.78 \mathrm{~cm}$ and thus somewhat more consistent with the recent diffusion length results.

It should be interesting to follow these lines and to check whether modal effects have given rise to errors in previous experiments.

Apart from the work on pure moderators there are many possibilities of expanding the method. Much work in the field of buckling determinations has to be done; there are also many possibilities for heterogenous system (systems composed of different moderators, systems composed of moderators at different temperatures). We finally mention the possibility of absorption measurements by the change in $\alpha$ observed when the substance investigated is dissolved in water. This method has first been used to determine the boron cross section ${ }^{51}$ ) and still has many unexplored possibilities ${ }^{52}$ ).

47) N. G. Sjöstrand, J. Mednis and T. Nilsson, Arkiv för Fysik 15 (1959) 471.

48) R. P. Belles, G. de Saussure and E. G. Silver, Trans. Am. Nucl. Soc. 3, 1 (1960) 155.

19) R. P. Belles, G. de Saussure and E. G. Silver, personal communication (1960).

50) W. M. Lopez, J. R. Beyster, R. E. Nather and J. L. Wood, Trans. Am. Nucl. Soc. 3, 1 (1960) 199.

51) G. F. von Dardel and N. G. Sjöstrand, Phys. Rev. 96 (1954) 1566.

52) J. Meadows and J. Whalen, WASH-1026 (1959) 1. 


\section{Prompt Neutron Period Measurements on Reactor Assemblies}

\subsection{GENERAL}

The general time behaviour of the thermal neutron flux in a multiplying medium after injection of a fast neutron burst is illustrated in fig. 12. After the burst injection a transition phase follows in which the thermal neutron

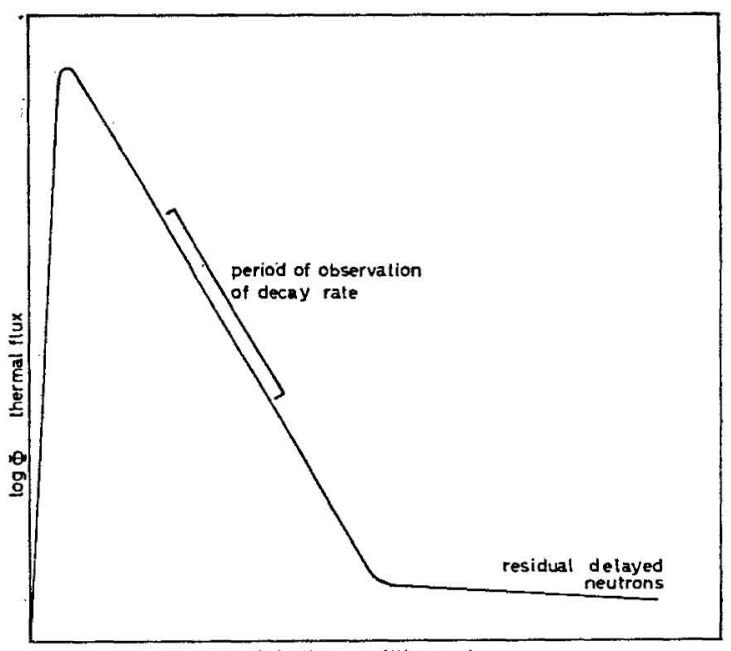

1 time after injection - milliseconds

Fig. 12. Time behaviour of thermal flux following injection of a fast neutron burst (from $\left.{ }^{56}\right)$ ).

population is established and the harmonic modes die out. In the next phase this initial thermal neutron population dies out exponentially with the prompt decay constant $\alpha$ of the system. After the decay of the prompt neutron group there remains a slowly decaying group due to residual delayed neutrons. The idea of pulsed experiments on reactor systems is to observe the prompt decay and to measure $\alpha$, which can be correlated to other reactor data. Under certain simplifying assumption, the following relation

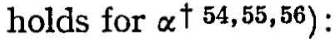

$$
\alpha=\frac{1}{l}\left[1-(1-\beta) K_{\mathrm{etr}}\right] \text {. }
$$

Here $l$ is themeangeneration time of thesystem, $K_{\text {eff }}$ is the effective multiplication factor, and

$\dagger$ We shall not deal here with the difficulties arising in reflected systems, nor shall we discuss the problems of "static" and "dynamic" reactivity ${ }^{53}$ ) interpretation of the experiments. $\beta$ the effective delayed neutron fraction $\left(\beta \approx 0.007\right.$ for $\mathrm{U}^{235}$ systems). $K_{\text {erf }}(1-\beta)$ is sometimes called $K_{\mathrm{p}}$, the prompt multiplication factor.

Eq. (3.1) permits different interpretations. In the more fundamental one, systematic measurements of $\alpha$ as a function of $B^{2}$ are made over a wide range of subcritical systems. For these systems, $l$ and $K_{\text {eff }}$ are calculated using multigroup techniques. These measurements allow a systematical check of these reactor computing techniques by comparing calculated and measured $\alpha$ vs. $B^{2}$-curves.

The other application aims towards reactivity calibrations on existing reactors or critical facilities. If we define the reactivity

$$
\rho=\frac{K_{\text {etr }}-1}{\beta}
$$

(in units "Dollar"), we have for systems close to critically

$$
\alpha=\frac{\beta}{l}[1-\rho] .
$$

The quantity $\beta / l$ can be determined by an $\alpha$ measurement on a system with known reactivity, particularly at delayed critical where we have $\rho=0$ and therefore

$$
\alpha=\alpha_{c}=\frac{\beta}{l} .
$$

We thus have

$$
\alpha=\alpha_{\mathrm{c}}(1-\rho) .
$$

Eq. (3.4) and (3.5) show that measurements of $\alpha$ on systems with known reactivity yield the generation time, while an $\alpha$ measurement on a system once its $\alpha_{c}$ is known gives its reactivity directly in "Dollars". This method can be used to calibrate control and safety rods on reactors and to measure reactivity contributions of absorbers or fuel elements.

Fig. 12 showed the time behaviour after the injection of a single neutron burst into a "clean" system, that is a system which had no other

53) B. E. Simmons, Nucl. Sci. Eng. 5 (1959) 254.

54) S. C. Fultz, Nucl. Sci. Eng. 6 (1959) 313.

55) J. Bengtson et al., Geneva 1958 P/1783.

56) B. E. Simmons and J. S. King, Nucl. Sci. Eng. 3 (1958) 595. 
neutron population than that caused by spontaneous fissions before the burst was injected. In an actual measurement it will be necessary to fire many bursts into the system before sufficient counting statistics have been reached. Periodic injection of neutron bursts into the system will however permit the long-living delayed neutron group to come into equilibrium thus causing a constant neutron background to build up. The ratio of the maximum neutron flux during the burst to the source-induced background is given by ${ }^{55}$ )

$$
1+\frac{\left[1-(1-\beta) K_{\mathrm{efr}}\right]^{2}}{2 \beta(1-\beta) K_{\mathrm{eff}}} \frac{T}{l}
$$

where $T$ is the repetition period of the pulsed source. In order to have this ratio sufficiently high, it is necessary to keep the repetition rate of the source low.

\subsection{INSTRUMENTATION}

Pulsed sources for reactor work have to be highly flexible. In order to inject neutrons into reactors, it is necessary to pass channels through thick shields, sometimes under very restricting room conditions. The desirable pulse frequencies are very low-of the order of $1 / \mathrm{sec-due} \mathrm{to} \mathrm{the}$ above-mentioned condition for high signal-tobackground ratio. The pulse intensities however must be high - of the order of $10^{6}-10^{7}$ neutrons per burst - in order to perform measurements in reasonably short times, and to overcome any background source neutrons present in the system from previous operation (e.g. long-lived photoneutron sources in $\mathrm{D}_{2} \mathrm{O}$ or beryllium systems). A source meeting these requirements is the "Pulsatron" pulsed neutron generatort. This generator, which is schematically shown in fig. 13, delivers 1-105 $\mu$ sec-bursts each of $10^{7}$ neutrons per second. The dimensions of the accelerator unit are $4 " \mathrm{OD} \times 18^{\prime \prime}$ length, thus making it readily usable in situations where space is very restricted. Of course, most of the accelerators mentioned in section 2.2 can also be used for reactor work. Fig. 13a shows the

† Manufactured by Kaman Aircraft Co., Nuclear Division, Colorado Springs, Colo.

t† Such neutron detectors are now commercially available.
PN 400-van de Graaff generator used as a pulsed neutron source for a subcritical assembly.

Due to the fact that pulsed experiments on reactors are done with low repetition rate but high intensity, the neutron detection and time analysis may become a difficult experimental problem. While some authors have used more conventional equipment like $\mathrm{BF}_{3}$ counters or fission chambers, others have employed typical high resolution detectors. Simmons and King56)

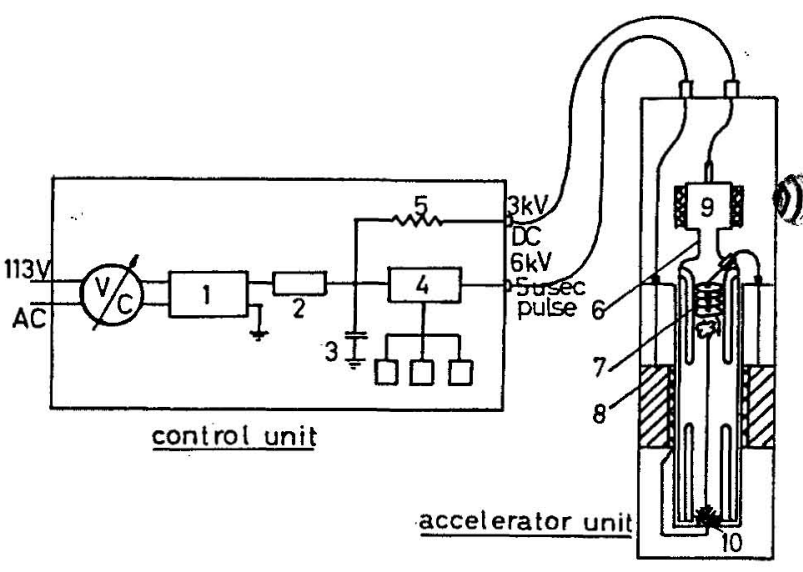
1. HV transformator
2. rectifier
6. VN accelerator tube
3. energy storage capacitor
4. thyratron
5. dropping resistor
7. ion source
8. 30-1 pulse tranformator
9. pump
10. target

Fig. 13.

The "Pulsatron" pulsed neutron generator(Kaman Nuclear).

have used a DuMont 6292 multiplier with a borated cathode $\left.{ }^{57}\right){ }^{\dagger \dagger}$. The $\alpha$-particles from the $\mathrm{B}^{10}(\mathrm{n}, \alpha) \mathrm{Li}^{7}$ reaction enter into the $\mathrm{Cs}-\mathrm{Sb}$ photocathode layer where they produce electron emission directly. This counter has high sensitivity and an extremely low deadtime (a small fraction of a microsecond). Keepin ${ }^{58}$ ) has proposed the use of loaded plastic and liquid scintillators and particularly of noble-gas scintillation counters. The latter have the advantage that they are extremely insensitive to $\gamma$-radiation and can be made very fast.

A very suitable time analyzer for work on reactor systems is the TMC 256-Channel Analyzer in connection with the \#212 pulsed

57) G. F. Erickson, S. G. Kaufmann and I. F. Pahis, IRE Trans. on Nucl. Sci. NS-3, No. 3 (1956).

58) G. R. Keepin, personal communication (1960). 
neutron plug in unitt, which is shown in fig. 14. This device has 256 analysis channels with a width adjustable between 10 and $2560 \mu \mathrm{sec}$. The only be achieved by electrostatic deflection of ion beams $\left.{ }^{10}\right)$. The overall time resolution of the neutron detection system should be of the order

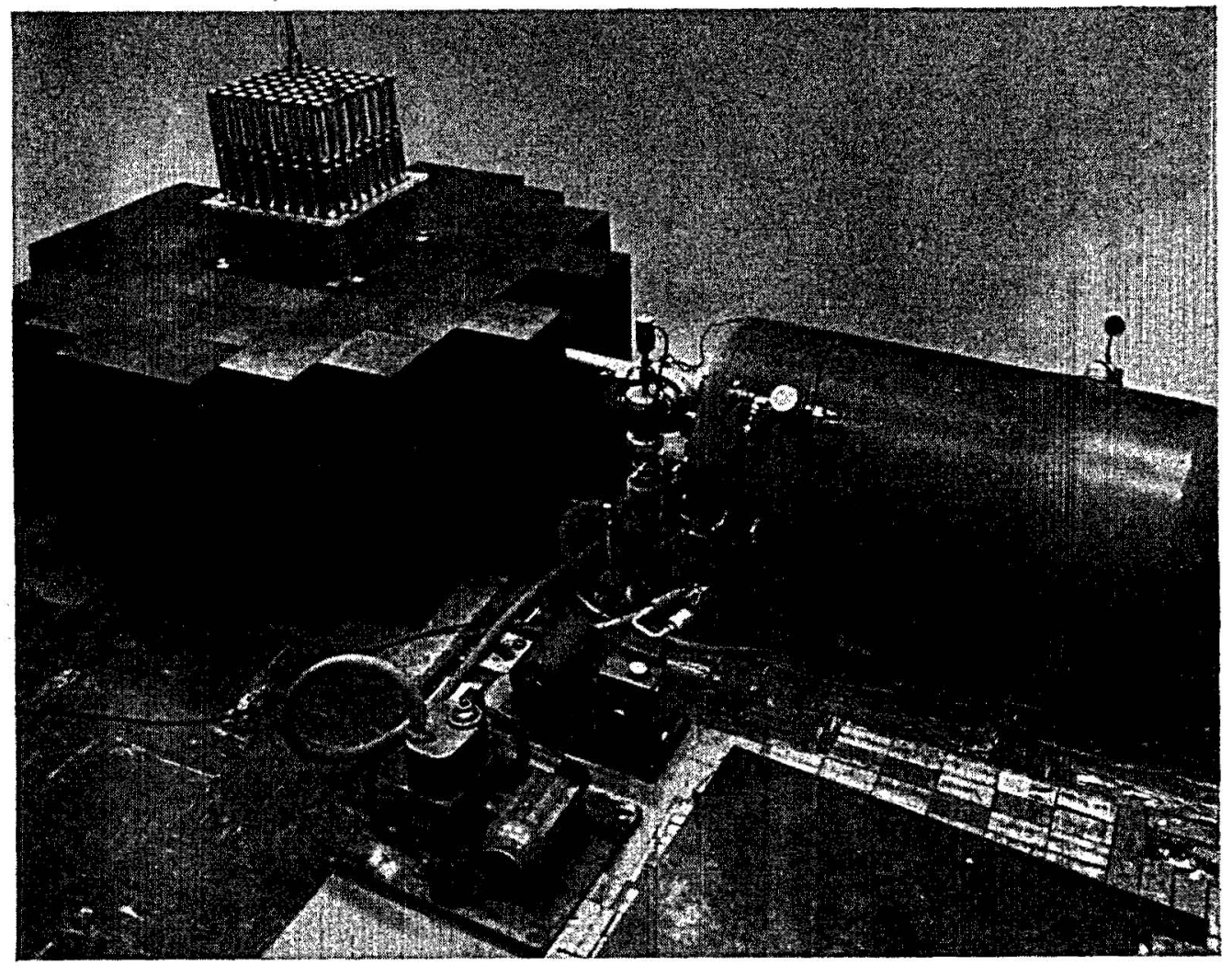

Fig. 13a: PN 400-Van de Graaff pulsed neutron generator used at Belgonucléaire, Brussels.

input deadtime is of the order of $3 \times 10^{-8} \mathrm{sec}$, thus making very high counting rates tolerable. The apparatus has facilities to register the preburst background and to introduce arbitrary delays between the source burst and the start of the registering period. Storage is done in a magnetic core memory. Read out is done by either a printer or a tape puncher. Another highresolution analyzer has been developed at Los Alamos $\left.{ }^{17}\right)$ with fifty time channels $(1 \mu \mathrm{sec}-10 \mathrm{sec}$ wide) and an input deadtime $<5 \times 10^{-8} \mathrm{sec}$.

Measurements on fast systems require special instrumentation. Neutron pulse lengths as short as several millimicroseconds are necessary due to the short decay times of these reactors. This can

$\dagger$ Manufactured by Technical Measurement Corporation, North Haven, Conn. of 1 millimicrosecond. A typical detection system developed for this type of work by Passel155) is shown in fig. 15.

\subsection{STUDIES OF DECAY RATES AS A FUNCTION OF BUCKLING}

A very careful study of unreflected, nearly homogenous assemblies consisting of graphite and enriched $(19.16 \%)$ uranium has been done by the Livermore group $59,55,54)$. Various loadings were obtained by intermixing 0.001 - and 0.002 inch thick uranium foils with 0.500 -inch thick graphite plates. Carbon- to uranium atomic ratios were $1,300,600,1200,2340$ and 9950:1 with an overall graphite density of

59) F. A. Kloverstrom and E. Komoto, UCRL -5477 (1959). 


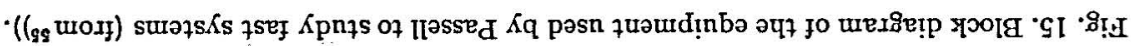

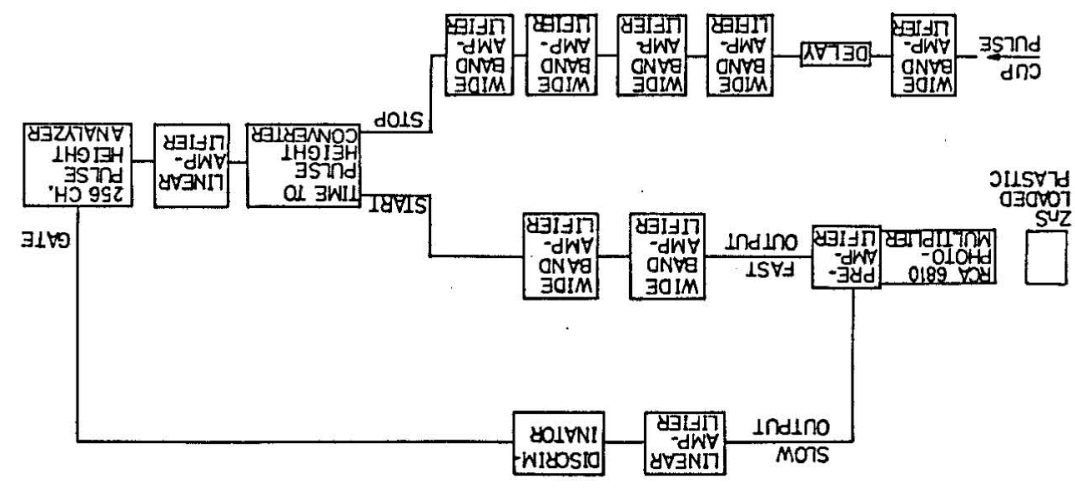

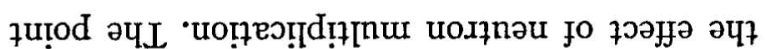

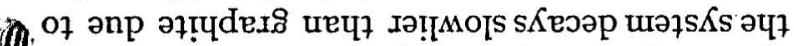

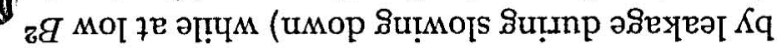

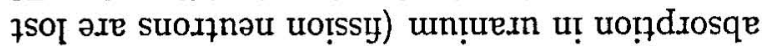

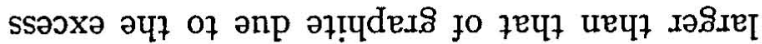

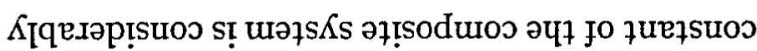

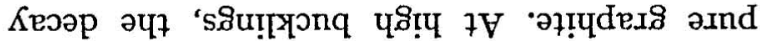

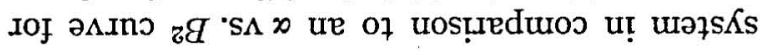
I :0Ћ

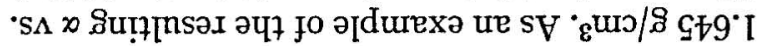

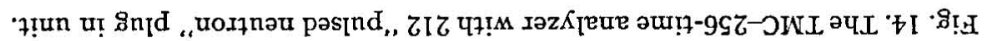
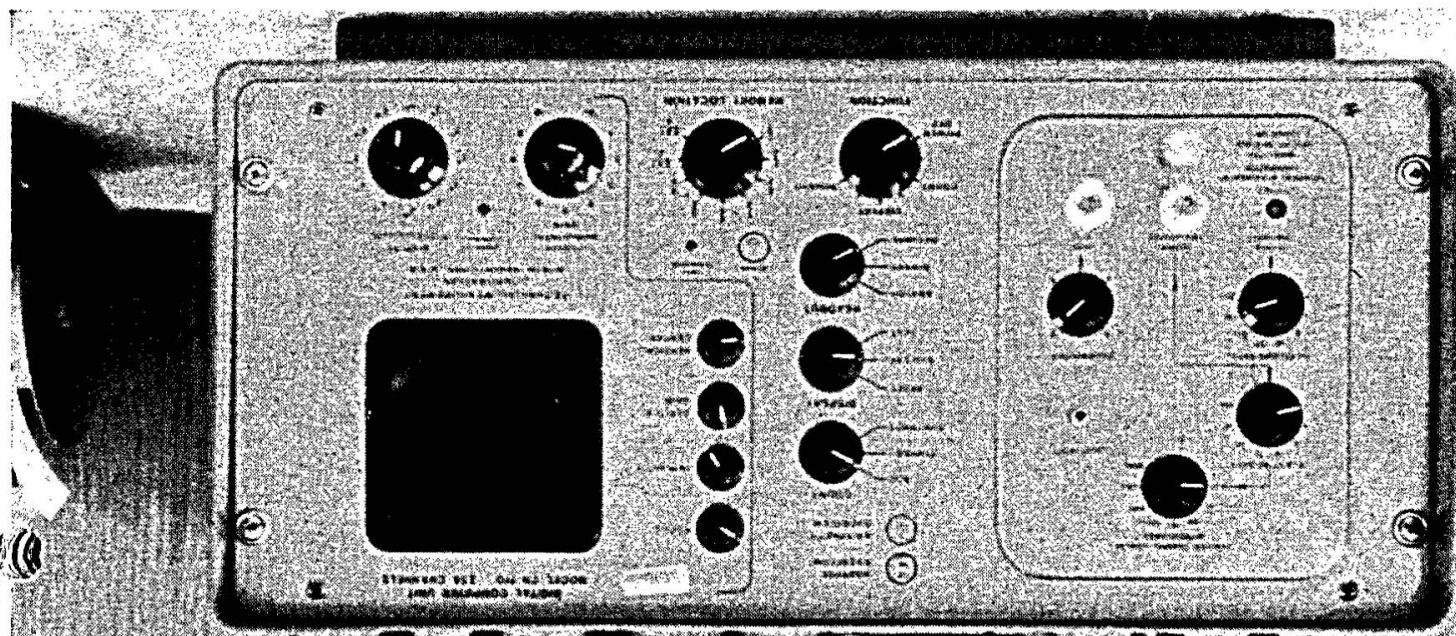

1

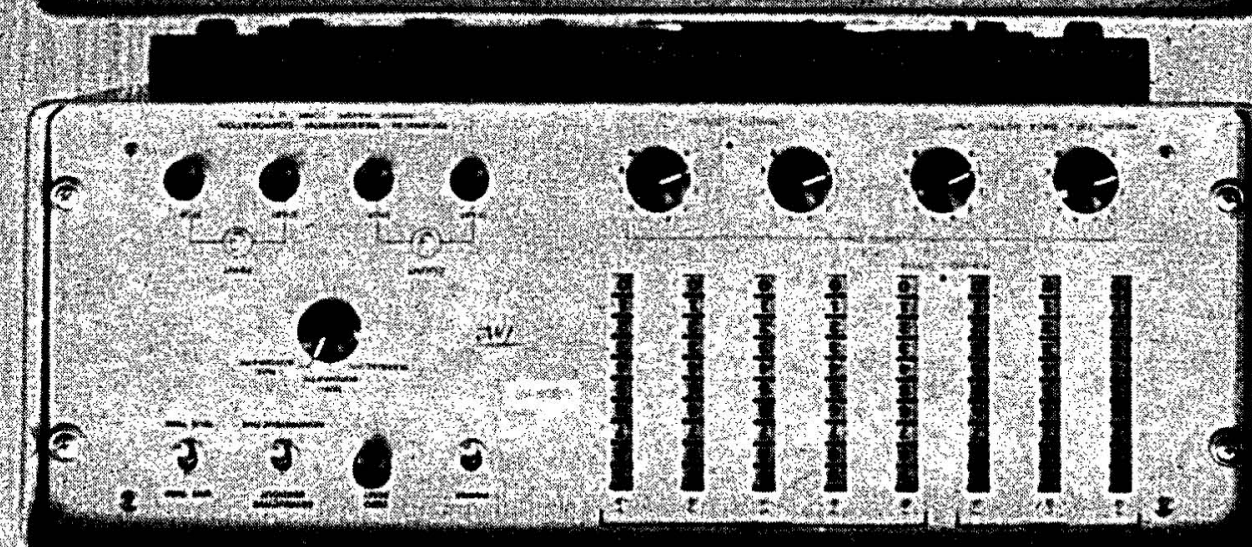


where the curve intersects the abscissa defines the "prompt critical" buckling.

Fultz ${ }^{54}$ ) has tried an interpretation of the obtained $\alpha$ vs. $B^{2}$ curves by means of a simple

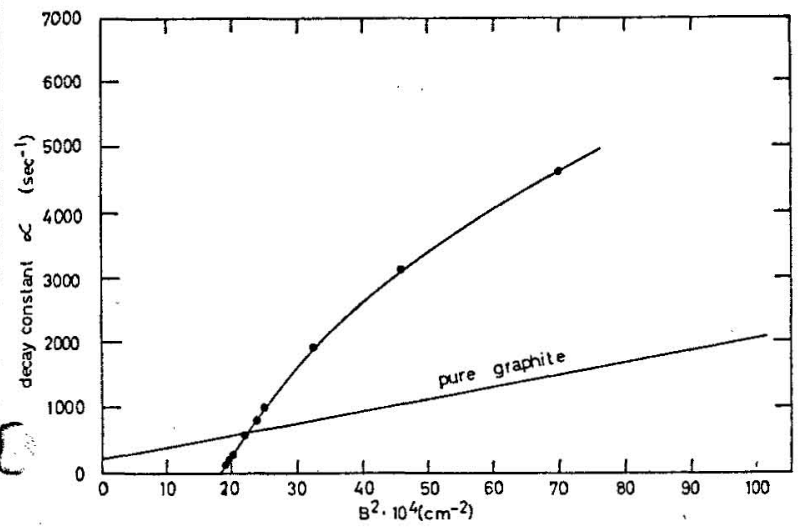

Fig. 16. Decay constant vs. buckling for graphite and for system with $\mathrm{C}: \mathrm{U}^{235}=2355: 1\left(\right.$ from $\left.\left.^{55}\right)\right)$.

2-group theory (one group representing fast, the other one thermal neutrons). A comparison of theory and experiment for the system with a $\mathrm{C}: \mathrm{U}$ ratio $9950: 1$ is shown in fig. 17 and shows

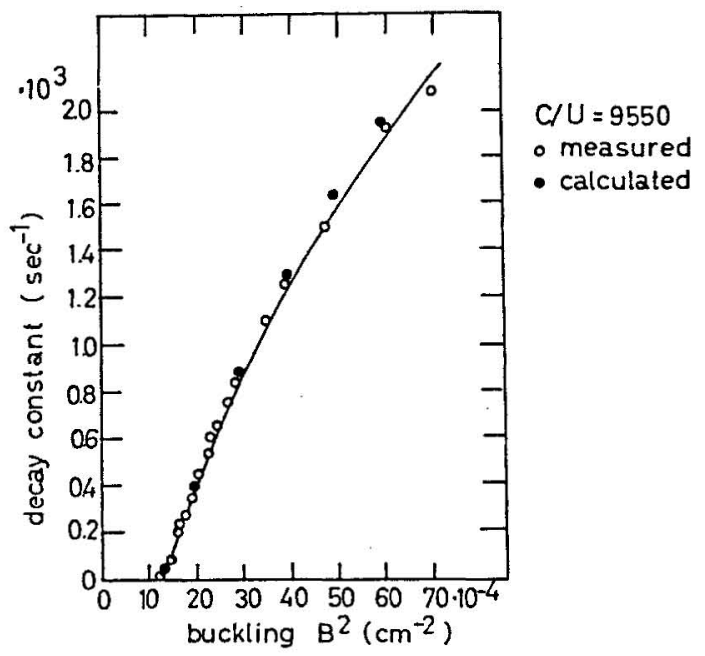

Fig. 17. Decay constant vs. buckling for a C: U ratio $9950: 1$, showing experimental and calculated points (from $\left.{ }^{54}\right)$ ).

a very good agreement. The agreement is not as good for the systems having lower $C: U$ ratio. As stated by Fultz, this may be due to the fact that only the 9950:1 system is "thermal" while the other system investigated have a considerably harder energy spectrum. For these systems, it may be necessary to use other group constants, especially for the "thermal" group. Studies on aqueous solutions of enriched uranyl fluoride, containing 53.0 and $26.5 \mathrm{~g} \mathrm{U}^{235}$ per liter, have been performed by Campbell and Stelson ${ }^{60}$ ).

\subsection{REACTIVITY CALIBRATIONS ON COMPLETE REACTOR SYSTEMS}

A calibration of the safety rods of the Swedish reactor $\mathrm{R} 1$ and a measurement of the $\mathrm{D}_{2} \mathrm{O}$ reactivity equivalent has been done by Sjöstrand $\left.{ }^{61}\right)$. Sjöstrand used a technique somewhat different from the one outlined in section 3.1; we shall not go into its details here. Calibrations of control rods on hydrogenous reactors have been done by Simmons and King56) and by the Oak Ridge group ${ }^{62,63}$ ). The latter group has also performed measurements of reactivity equivalents of fuel elements ${ }^{64}$ ).

As an example, we consider a control rod calibration which was done at the Bulk Shielding

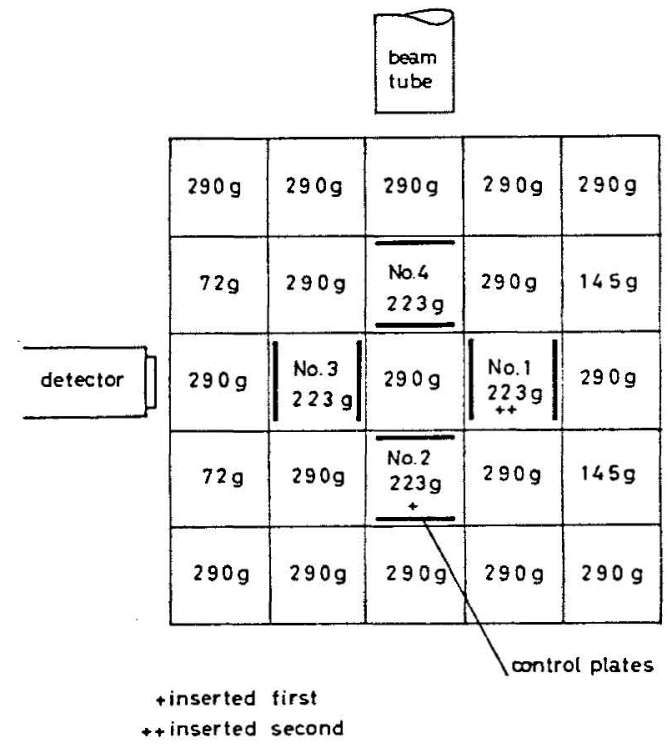

Fig. 18. BSR-II schematic core configurations for pulsed neutron measurement (from ${ }^{62}$ )).

60) E. C. Campbell and P. H. Stelson, ORNL-2204, 34 (1956).

61) N. G. Sjöstrand, Arkiv för Fysik 11 (1956) 233.

62) E. G. Silver et al., ORNL-2842 (1959) 35. 278.

$\left.{ }^{63}\right)$ E. G. Silver et al., Trans. Am. Nucl. Soc. 3, 1 (1960)

64) G. de Saussure, K. M. Henry and R. P. Belles, Nucl. Sci. Eng. (in press). 
Reactor (BSR II) at Oak Ridge ${ }^{62}$ ). The core of this "swimming pool' type reactor consists of 25 plate-type fuel elements as schematically shown in fig. 18. The control plate pairs to be calibrated are numbers 1 and 2 as shown in fig. 18. After $\alpha_{\mathrm{c}}$ had been determined by independent measurements, the decay curves with one and with both control plate pairs inserted were measured, they

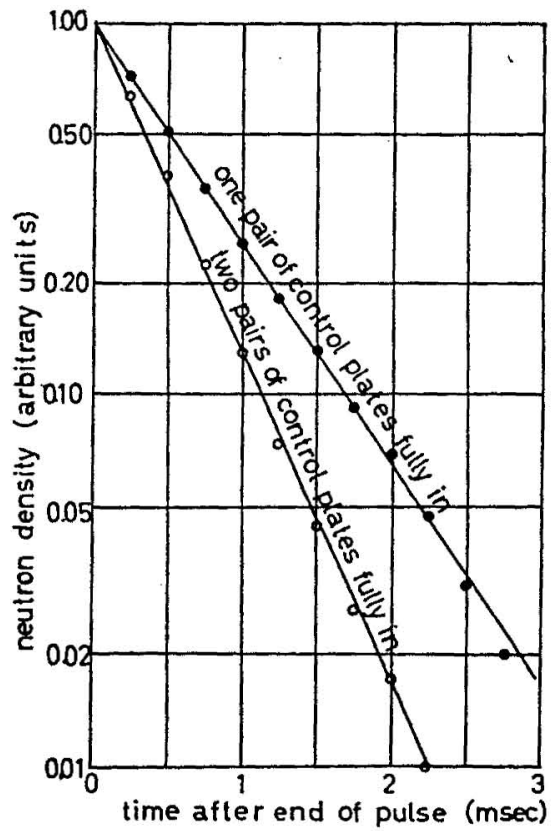

Fig. 19. Decay of the thermal neutron flux in the BSR-11 as a function of time after end of pulse for various subcritical conditions (after $\left.{ }^{62}\right)$ ).

are shown in fig. 19. With $\alpha_{\mathrm{c}}=3.13 \times 10^{2} \mathrm{sec}^{-1}$ and $\alpha\left(1\right.$ "in") $=(1.36 \pm 0.03) \times 10^{3} \mathrm{sec}^{-1}$; $\alpha\left(1+2\right.$ "in") $=(2.11 \pm 0.04) \times 10^{3} \mathrm{sec}^{-1}$ we find with eq. (3.5)

$$
\rho_{(1)}=-3.3 \pm 0.2 \$, \rho_{(1+2)}=-5.6 \pm 0.2 \$ \text {. }
$$

Since for reasons of symmetry $\rho_{1}=\rho_{2}$, we apparently have $\rho[1+2]<\rho[1]+\rho[2]$ which shows mutual shielding effects between the two control plate pairs. Using stable period measuring techniques and the inhour formula, reactivities as large as several dollars cannot be accurately measured. It is a special advantage of the pulsed technique that it permits this type of measurement to be done with good accuracy.

\subsection{FAST SYSTEMS; COMPARISON WITH ROSSI $\alpha$ METHOD}

Investigations on fast systems have been performed by Passell et al. 55,65 ) and by Bendt et al.66). The latter authors have studied prompt periods from the Godiva fast critical assembly at Los Alamos. The measurements were performed at two different positive reactivities between delayed and prompt critical, the reactivities being accurately determined from measurements of the (stable) reactor period. The resulting $\alpha$

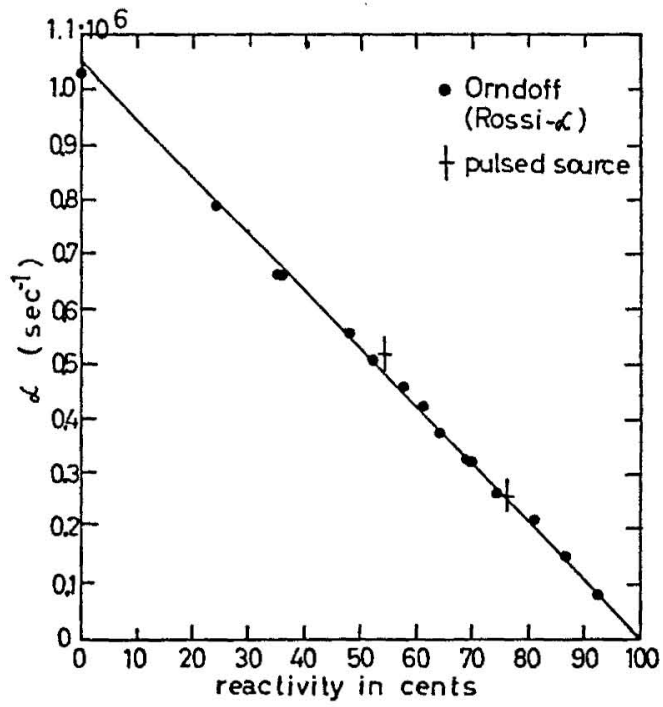

Fig. 20, $\propto$ measurements on Godiva, plotted against reactivity (from $\left.{ }^{66}\right)$ ).

values are plotted in fig. 20 as a function of reactivity, together with $\alpha$-values independently determined by Orndorff67) using the "Rossi- $\alpha$ method". This method, which has been frequently used for measurements on fast and intermediate reactor systems ${ }^{55}$ ), consists in a determination of $\alpha$ by analysis of time intervals between pairs of counts in a steady state, low power reactor system. A neutron detector placed in or near a chain-reacting system will present counts which are in part nonrandom due to the time correlation between neutrons having a

${ }^{65}$ ) L. Passel, J. Bengston and D. C. Blair, UCRL -4808 (1957).

$\left.{ }^{66}\right)$ P. J. Bendt, H. J. Karr and F. R. Scott, Nucl. Sci. Eng. 4 (1958) 703.

67) J. D. Orndorff, Nucl. Sci. Eng. 2 (1957) 450. 
common ancestor. The advantage of this method relative to the pulse method is apparently the fact that it does not involve a pulsed source, the equipment thus being much simpler and cheaper. The method is however only applicable in systems with a very short generation time which are close to criticality, otherwise the background problems will be increasingly difficult ${ }^{55}$ ). It is seen from fig. 20 that pulse method and Rossi$\alpha$-method give results which agree extremely well.

A comparison of the Rossi- $\alpha$-method and the pulse method for a measurement of the neutron generation time in the Brookhaven Beam Research Reactor (BBRR) critical facility, a slightly undermoderated, enriched uranium $\mathrm{D}_{2} \mathrm{O}$ system, has been carried out by Price et al. $\left.{ }^{68}\right)$.

\section{Measurements of Neutron Spectra in Moder- ators and Reactor Systems by the Time-of- Flight Method}

\subsection{GENERAL}

Perhaps the most interesting application of pulsed neutron sources as far as physics is concerned is the study of neutron thermalisation processes in moderators and reactors. Such investigations yield information on the basic interaction processes between neutrons and bound atoms which are very important for solid state physics. On the other hand they make possible calculations of reactor spectra which have to be done in order to predict the longterm behaviour of power reactors.

If a fast neutron is born in a moderating medium it will successively pass through different stages of the slowing down and thermalisation process until it is finally thermalized, that means in an asymptotic state where its mean energy does not change with time. The following questions as to the thermalisation process arise:

a. What is the energy spectrum $\Phi(E, t)$ of the neutron as a function of time $t$ ? .

b. What especially is the asymptotic energy

$\dagger$ The "energy spectrum" of a neutron can of course be only defined in the sense of an "average spectrum" if many neutrons have started at $t=0$. spectrum $\Phi_{\mathbf{a s}}(E)$ reached at the end of the thermalisation process?

c. What is the average spectrum of the neutron over its lifetime in the moderator?

Questions a. and b. are important mainly for the fundamental aspects of neutron thermalisation physics, while $\mathrm{c}$. has a direct bearing on reactor spectra since it is the spectrum observed in a stationary assembly with steady neutron sources. All three questions can be answered by means of pulsed neutron sources. In each case, very intense neutron bursts are injected into the system under investigation, and neutrons from the moderator are allowed to enter into a neutron flight path about 10 meters long. Since the energy region of interest is about $10^{-2}-10^{2} \mathrm{eV}$, and since a $1 \mathrm{eV}$ neutron has a flight time of $70 \mu \mathrm{sec} / \mathrm{meter}$, sufficient resolution can be obtained when gate widths of $\leq 50 \mu \mathrm{sec}$ are used.

Now in order to answer question a., a mechanical interrupter (slow chopper) is placed between the moderator and the flight path which is synchronized with the pulsed source in a way that it passes a short (a few $\mu \mathrm{sec}$ ) burst of neutrons at a selected delay time $t$ after the fast neutron burst injection. By varying $t, \Phi(E, t)$ can be completely determined. This is the principle of the elegant "neutron life history experiment" which was proposed by Poole ${ }^{69}$ ) and is currently being done at Harwell. Since $t$ can be made large, the measurement can be extended into the asymptotic region, thus answering question $b$. also.

If it is desired to observe only the asymptotic spectrum a somewhat different, technique can be used70). A "shutter" prevents neutrons from entering the flight path during the thermalisation process and opens only after complete equilibrium has been reached. We shall discuss this method and its application to water systems in section 4 .

The method of taking the "average" spectrum depends on the neutron lifetime of the system. If this is short (of the order of 50-100 $\mu \mathrm{sec}$ ) as in hydrogenous moderators, all the neutrons

68) G. Price, personal communication (1960).

69) M. J. Poole, Symp. on Application of Pulsed Neutron Techniques, Berkeley (1958) UCRL-5665.

70) K. H. Beckurts, Internal Karlsruhe report (1960). 
from the moderator are admitted to the time-offlight analysis, the system thus performing the time integration itself. This method was first used by Poole ${ }^{71}$ ) and will be reviewed in section 4.3. If the system has a long neutron lifetime like $\mathrm{D}_{2} \mathrm{O}$ or graphite, this method cannot be used since unreasonably long flight paths would be necessary in order to achieve good resolution. For this case, a very interesting "sampling". technique has been developed by Beyster et al. ${ }^{72}$ ) which we shall discuss later.

All these investigations use rather high neutron source intensities, the experimental equipment is almost one order of magnitude more complex and expensive than for the simple moderator studies outlined in section 2. However, before the arrival of these advanced techniques very nice experimental work has been done using low intensity neutron sources and a simple transmission method in order to study the time behaviour of the mean neutron energy during the thermalisation process. The reader is referred to the early work of von Dardeli3), which represents one of the most important contributions to pulsed neutron source research.

\subsection{INSTRUMENTATION}

Neutron spectra determinations by the time-offlight technique require extremely high neutron intensities, at least of the order of $10^{9}-10^{10}$ per burst. Most work has therefore been done using high intensity electron linear accelerators. Two major facilities are in use now: The new Harwell accelerator ${ }^{3}$ ) and the General Atomic accelerator $\left.^{74}\right)$. Both have electron energies of the order of $25 \mathrm{MeV}$ and deliver microsecond electron pulses with currents above $100 \mathrm{~mA}$ to neutron producing targets, the neutron yield thus exceeding $10^{10} / \mathrm{burst}$. Since the repetition rate of these accelerators is normally too high for spectrum observations, and since it is desired to operate other experiments simultaneously, pulsed beam deflection magnets are used which deliver selected electron pulses to the neutron target of the system under investigation.

We shall not go into the details of the construction of choppers which are sometimes used for these experiments, nor shall we deal with the problems of detectors and time analyzers since these are the same as used in standard slow neutron spectroscopy.

\subsection{MEASUREMENT OF THE "INTEGRAL" SPECTRUM}

Fig. 21 shows the arrangement used by Poole ${ }^{71}$ ) for the investigation of neutron spectra from water and from boric acid solutions.
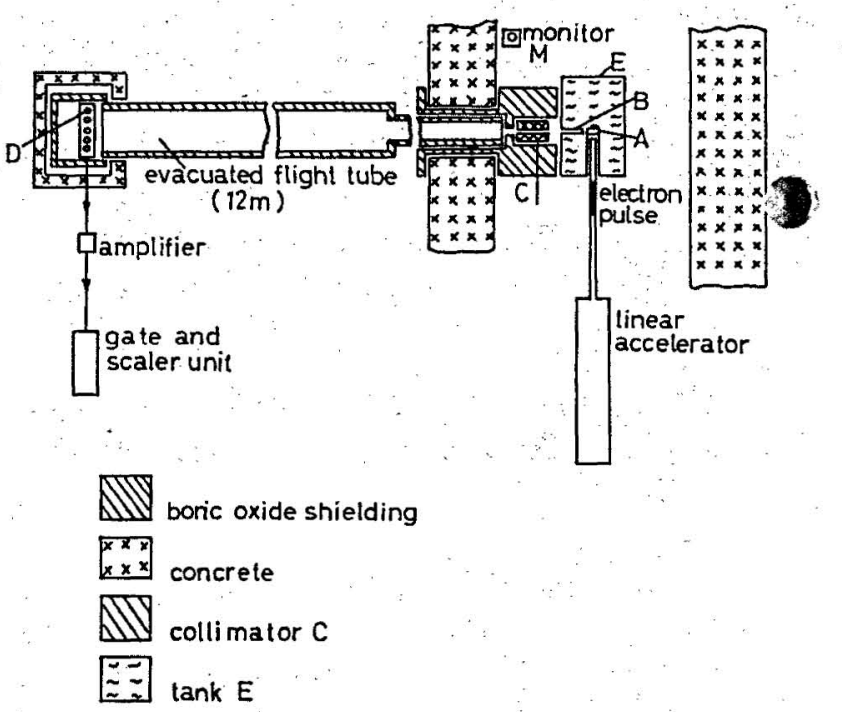

Fig. 21. The arrangement used by Poole for spectra measurements on water and boric acid solutions (from ${ }^{71}$ )).

Neutrons are extracted from the system by means of a reentrant channel. A very carefully designed collimator at the entrance of the flight path is of vital importance in order to prevent 3 unwanted neutrons to enter. Also, great care has to be taken in shielding the flight path and the detectors against room-scattered neutrons. The neutron spectrum thus observed is the spectrum leaking at the end of the reentrant channel in one particular direction. Since the desired quantity is the spectrum averaged over all directions, it is necessary to apply corrections which

71) M. J. Poole, J. Nucl. En. 5 (1957) 325.

72) W.M. Lopez, J. R. Beyster, R.E. Nather, R.B.Waiton and J. L. Wood, Trans. Am. Nucl. Soc. 3, 1 (1960) 173.

$\left.{ }^{73}\right)$ G. F. von Dardel, Trans. Roy. Inst. Technol., Stockholm 75 (1954).

74) J. R. Beyster, J'. L. Wood, W. M. Lopez and R. B. Walton, Trans. Am. Nucl. Soc. 3, 1 (1960) 157. 


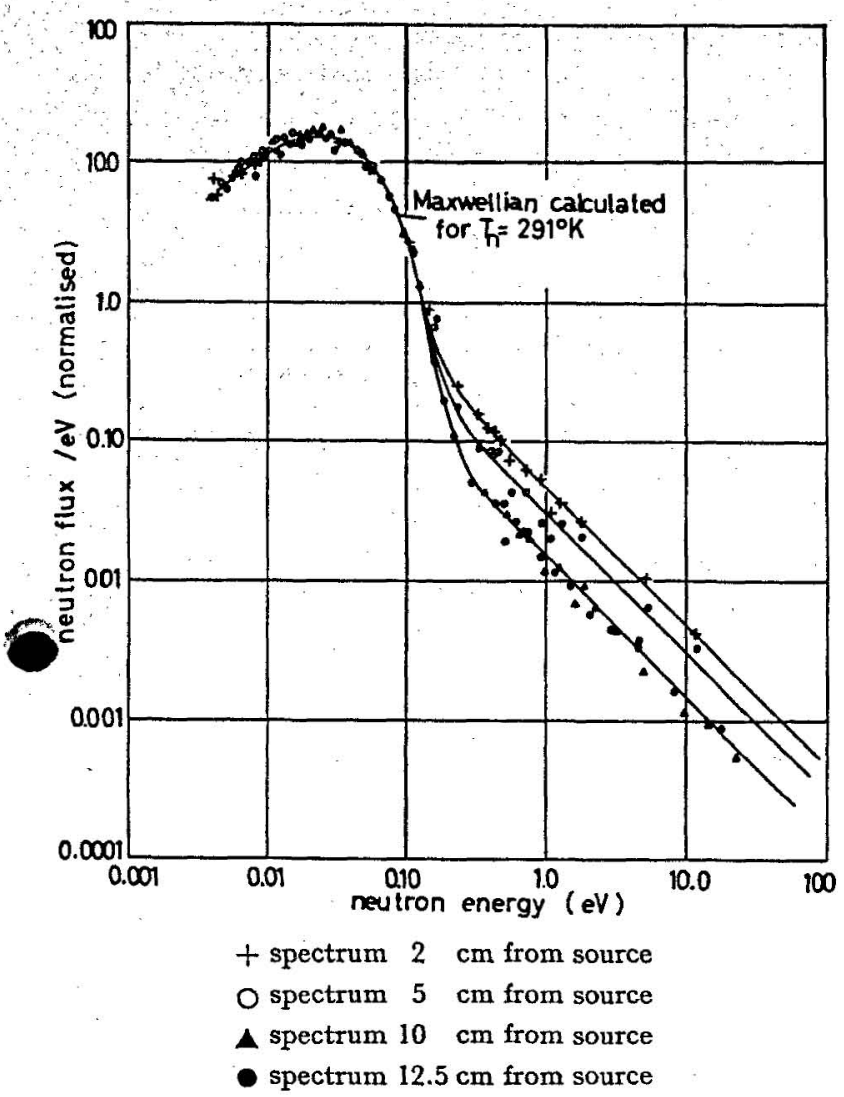

Fig. 22. Flux spectra in water of room temperature (from ${ }^{71}$ ))

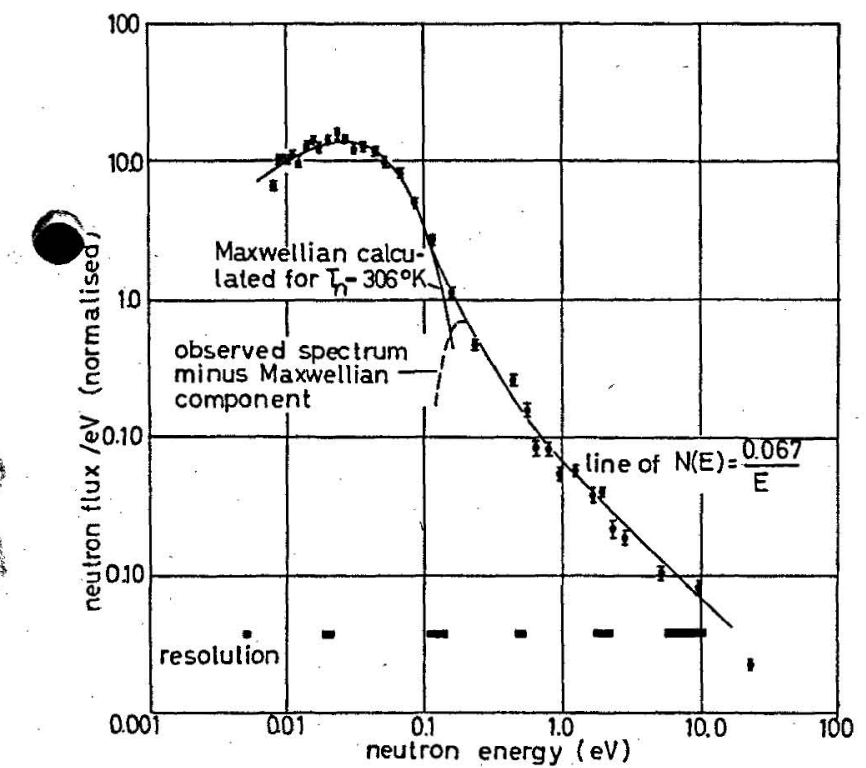

Fig. 23.

Flux spectrum in boric-acid solution at room temperature; 1.5 barn capture cross section per $\mathrm{H}$-atom present (from $\left.{ }^{71}\right)$ ). depend on the flux gradient at the observation point. Fig. 22 shows the flux spectrum obtained from pure water at different distances from the source. It is seen that at distances above $10 \mathrm{~cm}$ equilibriumisreached which indicates the presence of the "infinite homogenous medium spectrum". This spectrum can be decomposed into a Maxwellian region at low energies, a transition region and a $1 / E$-tail extendirig to higher energies. Spectra obtained from two boric acid solutions are shown in figs. 23 and 24. It is seen that the "neutron temperature" of these spectra exceeds the moderator temperature considerably which is a consequence of the strong "hardening".

Beyster et al..$^{74}$ ) have measured neutron spectra in different aqueous solutions in polyethylene and in zirconium hydride by the same technique. As an example we present from their recent work the spectra obtained from cadmium sulfate solutions (fig. 25). Since cadmium has a resonance at $0.18 \mathrm{eV}$, a bump is expected to appear in the spectra at this energy. This is indeed present, as seen especially at the higher cadmium concentrations. In fig. 25, the measured spectra are also compared to spectra calculated using two different "thermalisation kernels" for water. One of these is the "free hydrogen kernel" as derived by Wigner and Wilkins ${ }^{75}$ ) while the other, developed by Nelkin ${ }^{76}$ ) takes into account the chemical binding of hydrogen in water in an approximate manner. It is seen that the "bound hydrogen kernel" calculations give very good. agreement with the measured spectra.

We cannot go further into the details of the experimental work nor can we discuss here the status of thermalisation theory in explaining the measured spectra. These questions, as of 1958, are extensively discussed in the above-mentioned review article ${ }^{13}$ ). However some remarks as to the intercomparison of these techniques to stationary chopper methods should be made: Neutron spectra can also be measured by exciting the assembly under investigation with neutrons from a reactor and by chopping the beam of emerging neutrons in order to perform

75) E. P. Wigner and J. E. Wilkins, AECD 2275 (1948).

76) M. S. Nelkin, General Atomic Report GA-1063 (1960). 
a time-of-flight analysis. This method has been applied to water systems by Stone and Slovaczek $^{77}$ ) who found results which are in general agreement with Poole's measurements. The pulse method has the disadvantage that it can be used only on systems with a short die-away time of the neutrons while the chopper method can be used for all systems. The advantage of the pulse method over chopper-reactor methods is that easily altered geometric and a large range of parameters can be used; since for a chopper method fluxes between $10^{8}$ and $10^{10} / \mathrm{cm}^{2} \mathrm{sec}$ are necessary, certain contamination problems arise, especially if the system under investigation contains nuclear fuel. It seems therefore reasonable to use the pulse method on as many systems as possible, eventually with flight path lengths up to $100 \mathrm{~m}$ and at the expense of intensity and resolution.

An elegant solution to the problem of neutron spectrum measurements on long living assemblies consists in the use of a chopper which samples short neutron bursts from the decaying assembly. In order to take a correct average over the spectrum of the assembly the delay time between the burst injection and the chopper opening is varied in such a way that the chopper scans with equal probability all portions of the neutron die away history in the assembly. This has been achieved by Lopez, Beyster et al.72) who use the chopper window as a reference point in time and generate a time delay, based on the chopper angle, to trigger the accelerator. The system has been used for preliminary experiments on graphite so far. It may open the possibility of investigating all systems by the pulsed source method.

\subsection{A STUDY OF THE "ASYMPTOTIC" SPECTRUM IN WATER}

In order to prove the "diffusion cooling effect" (section 2.1.) directly by observations of spectra, Beckurts ${ }^{70}$ ) has performed measurements of the asymptotic neutron spectrum in pure water assemblies as a function of buckling.

${ }^{77)}$ R. S. Stone and R. E. Slovaczek, Nucl. Sci. Eng. 6 (1959) 466 .
The experimental arrangement is shown schematically in fig. 26. A neutron source emits bursts of neutrons (108 neutrons/burst) into small water systems. During the slowing down and

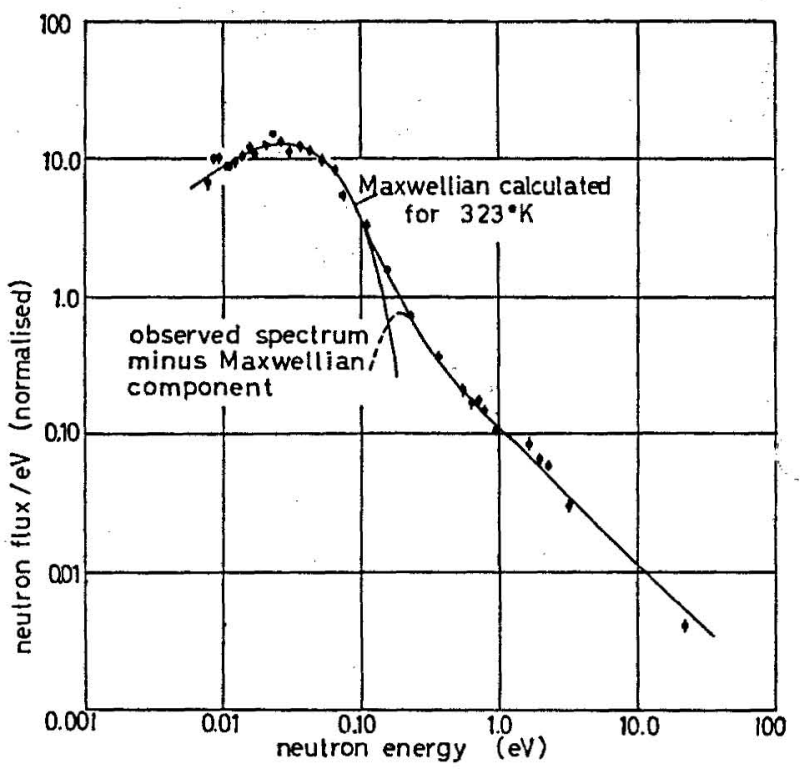

Fig. 24. Flux spectrum in boric-acid solution at room temperature; 2.9 barn capture cross section per $\mathrm{H}$-atom present (from $\left.{ }^{21}\right)$ ).

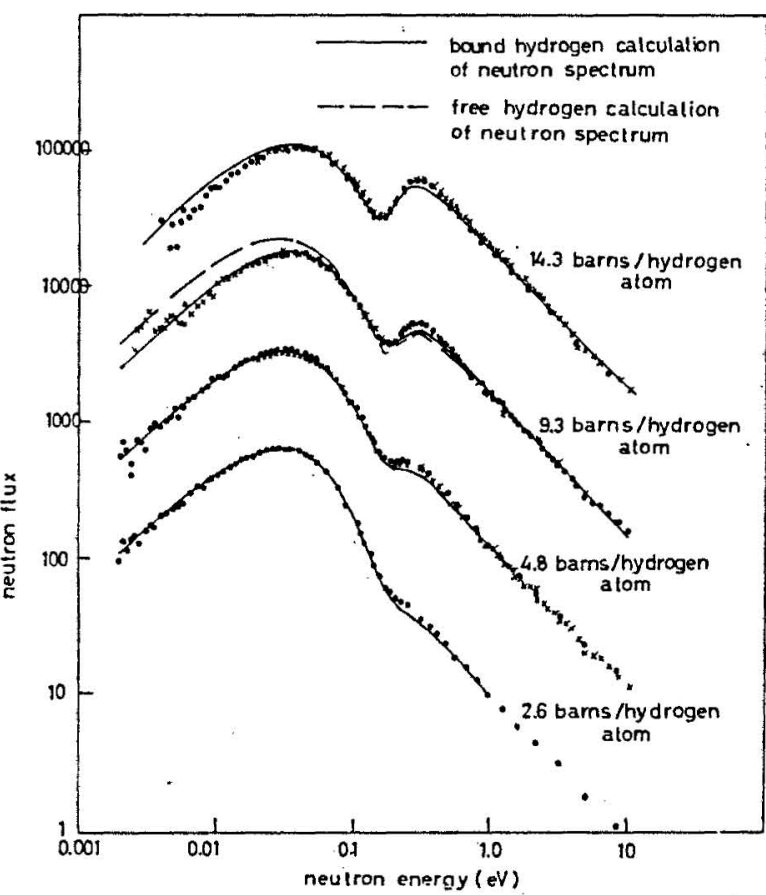

Fig. 25. Neutron spectra in water poisoned with cadmium sulfate of different concentrations (from ${ }^{74}$ ). 
thermalisation process, a shutter synchronized with the source prevents neutrons from entering the time-of-flight analyzer. It opens after the asymptotic state has been reached; since the thermal neutron population dies out successively in a time short compared to the neutron flight

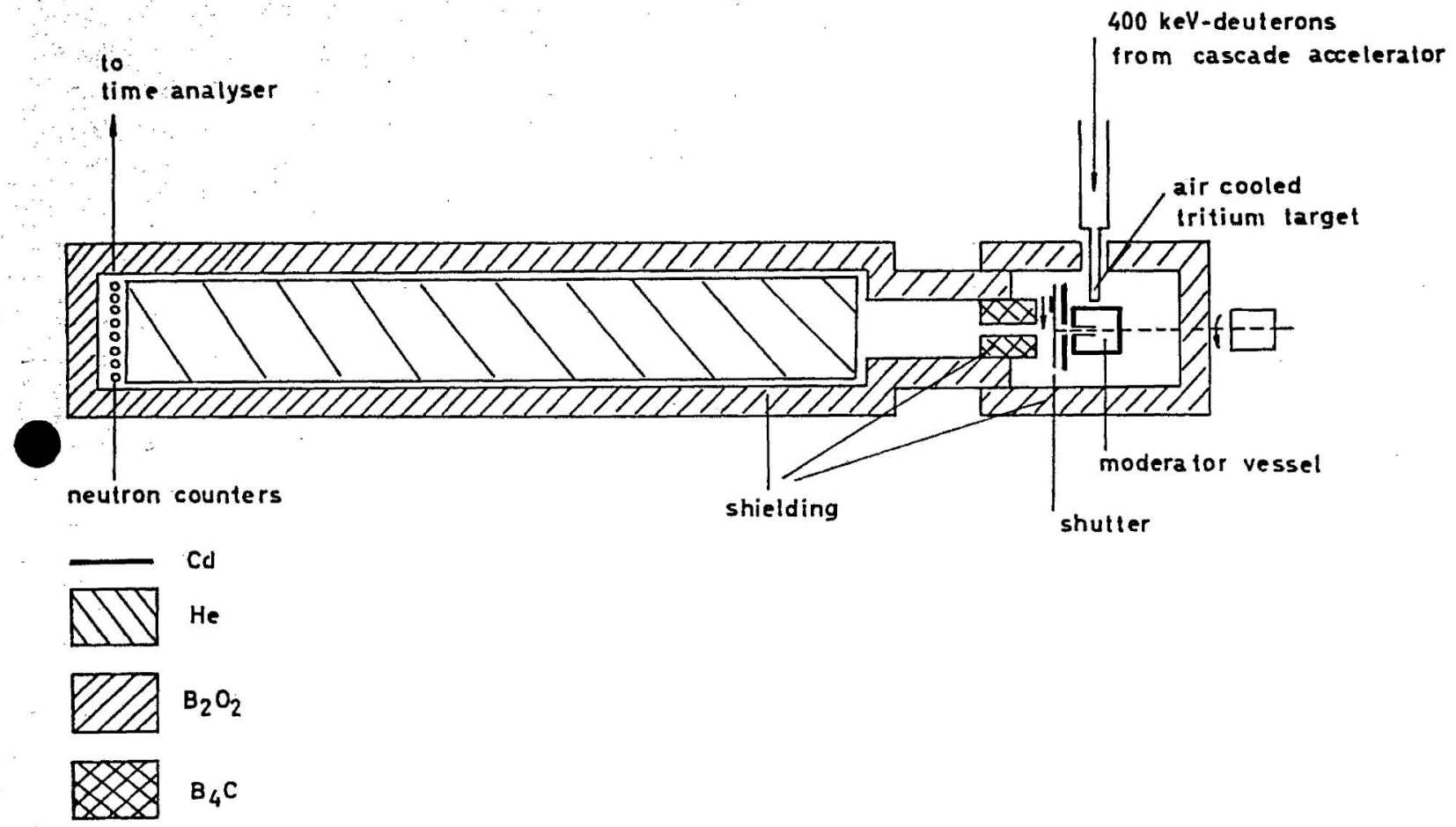

Fig. 26. Arrangement for observation of "diffusion cooling" in water.

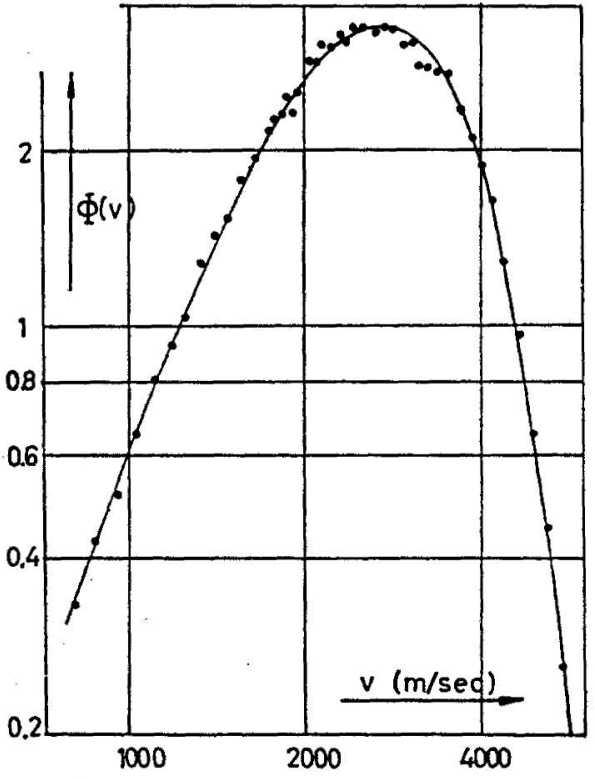

Fig. 27. The asymptotic spectrum from the center of a $(15 \mathrm{~cm})^{3}$-water cube. Full curve: Maxwellian with moderator temperature.

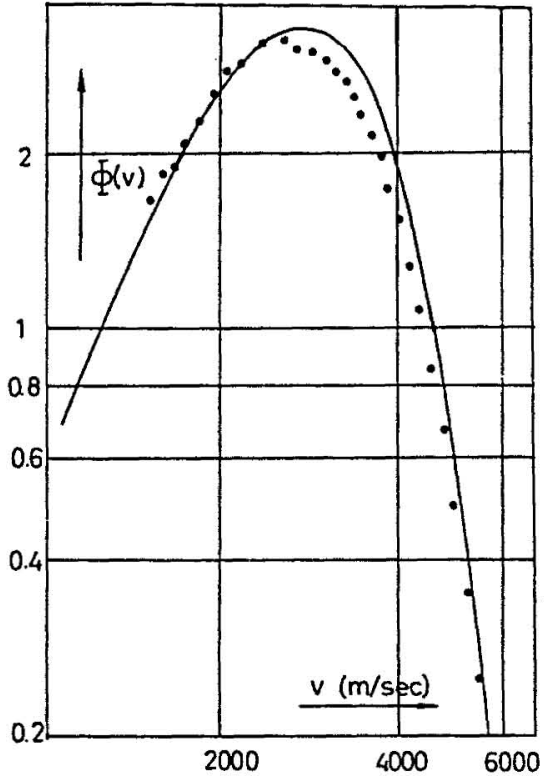

Fig. 28. The asymptotic spectrum from the center of a $(5 \mathrm{~cm})^{3}$-water cube. Full curve: Maxwellian with moderator temperature. 